\title{
Multi-objective approach for sustainable ship routing and scheduling with draft restrictions
}

Keywords - Carbon Emission, Fuel Consumption, Maritime logistics, Mixed Integer NonLinear Programming model, NSGA-II, Ship's Draft restriction, Ship Routing and Scheduling.

\begin{abstract}
This research addresses the sustainability and safety related challenges associated with the complex, practical and real time maritime transportation problem and proposes a multiobjective mathematical model integrating different shipping operations. A mixed integer nonlinear programming (MINLP) model is formulated considering different maritime operations such as routing and scheduling of ships, time window concept considering port's high tidal scenario, discrete planning horizon, loading/unloading operation, carbon emission from the vessel and ship's draft restriction for maintaining the vessel's safety at the port. The relationship between fuel consumption and vessel speed optimization is included in the model for the estimation of the total fuel consumed and carbon emission from each vessel. Time window concept considered in the problem aims to improve the service level of the port by imposing different penalty charges associated with the early arrival of the vessel before the starting of the time window and vessel failing to finish its operation within the allotted time window. Another practical aspect of the maritime transportation such as high tide scenario is included in the model to depict the vessel arrival and departure time at a port. Two novel algorithms - Non-Dominated Sorting Genetic Algorithm II (NSGA-II) and Multi-Objective Particle Swarm Optimization (MOPSO) have been applied to solve the multi-objective mathematical model. The illustrative examples inspired from the real-life problems of an international shipping company are considered for application. The experimental results, comparative and sensitivity analysis demonstrate the robustness of the proposed model.
\end{abstract}

\section{INTRODUCTION}

The United Nations Conference on Trade and Development (UNCTAD)[2] stated that international shipping carries $80 \%$ of world trade. In 2013, the total volume of world trade increased by $4.6 \%$ and reached up to 160 million twenty-foot equivalent units (TEUs) [3], and, by 2014, global containerized trade grew by 5.3\% and reached 171 million TEUs [4]. Containerized cargos (containers) are transported on regularly scheduled service routes of shipping companies. Standardized sea containers transport manufactured goods, dry commodities (coffee, tea, etc.) and refrigerated cargo (meat, fruit, fish, etc.). As global trade grows, there is increasing interest among researchers about the real and complex problems associated with routing and scheduling of containerized vessels. Most of the past research has focused primarily on ship routing and scheduling, bunker fuel consumption or ship draft restrictions. 
Despite the growing demands on the industry, only a minor proportion of the literature related to shipping logistics has taken into consideration the environmental sustainability issues pertaining to the mitigation of fuel consumption and carbon emissions. Due to climate change, there is a greater need than ever before to incorporate environmentally sustainable practices into the domain of maritime logistics.

This research aims to bridge the research gap and presents a mathematical model with multiple objectives addressing the intricacies of ship routing and scheduling, the time window concept and also considers the effects of carbon emissions as well as draft restrictions on vessels at different ports. The slow steaming policy is an important operational strategy incorporated to compute the total fuel consumption of a ship. Vessel draft restrictions are designed to prevent ships from travelling to ports during low tide for safety reasons. The multi-objective mathematical formulation developed in this paper is solved using Nondominated Sorting Genetic Algorithm II (NSGA-II) and Multi-Objective Particle Swarm Optimization (MOPSO).

This paper is organised as follows: Section 2 discusses background information and presents a literature review; Section 3 entails the problem description and also formulate the mathematical model; Section 4 contains the proposed solution methodology; Section 5 presents the results and a discussion; and Section 6 concludes this research paper and outlines the future scope of research.

\section{BACKGROUND and LITERATURE REVIEW}

This section provides relevant background information and a literature review covering areas including shipping emissions, slow streaming strategy, ship routing and scheduling, the time window concept and ship draft restrictions.

\subsection{SHIPPING EMISSIONS}

In the domain of maritime logistics, air pollution from vessels is a critical research topic. Kontovas et al. [5] reported that container ships are among the biggest air polluters as these emit a significant amount of carbon. Buhaug et al. [6] mentioned that of 4,100 registered vessels operating throughout the world, 4\% are container carrying ships. In 2007, 230 million metric tons (Mmt) of $\mathrm{CO}_{2}$ was emitted and $70 \mathrm{Mmt}$ of fuel was consumed by registered vessels [6]. The International Maritime Organization (IMO) has performed several comprehensive analyses to estimate the level of carbon emissions in international shipping. It observed that the container vessels emitted around 205 million tons of CO2 in 2012, nearly 40 and 80 million tons more than bulk carriers and oil tankers, respectively [6]. Cullinane et al. [7] reported that the total fuel consumed in maritime transportation ranges from 279-400 million tons per year. Hence, the IMO has stressed the importance of addressing possible measures to reduce carbon emissions in maritime shipping. 


\subsection{SLOW STEAMING STRATEGY}

The slow steaming policy is an important operational measure for mitigating fuel consumption and carbon emissions to deal with decarbonisation and increasing fuel prices. Sustainability has a significant influence on the design of a company's business model when it comes to addressing environmental issues [1]. Maersk Line, a global container shipping company, implemented a slow steaming policy in 2009 and has since benefitted from a carbon emissions reduction as well as fuel savings of 22\% [8]. Fagerholt et al. [9] emphasised the importance of reducing fuel consumption costs which can amount to around $50 \%$ of the operating costs of a global shipping company. Other container shipping companies have also started adopting a speed optimization strategy to reap environmental benefits by lowering their carbon emissions. Yao et al. [10] studied the non-linear relationship between fuel consumption and vessel speed for different sizes of containerships. Several research works [11 and 12] have considered the speed optimization strategy in vessel routing models to mitigate carbon emissions and fuel consumption. Norstad et al. [13] presented a formulation to deal with a problem pertaining to tramp ship routing and scheduling considering vessel speed as a decision variable. They adopted the speed optimization strategy to estimate the total amount of fuel consumed in port and at sea. Several authors have studied the implications of the slow steaming strategy on maritime logistics in terms of reducing the environmental effects associated with shipping [14]. In the context of maritime transportation, other researchers have also examined the impact of different vessel speed models on lowering greenhouse gas emissions [15]. Aydin et al. [16] focused on the speed optimization problem, taking into consideration uncertain service time and developed a dynamic programming model by discretizing the port arrival times. Recently, Mansouri et al. [17] presented a comprehensive review examining sustainability aspects in maritime shipping and investigating from the perspective of multiple-objective optimization to maintain a proper trade-off concerning economic, environmental and service related aspects. In the context of liner shipping services, other researchers have simultaneously dealt with shipping emissions, service reliability and expected cost [18]. They have developed a stochastic multiobjective optimization model depicting the conflicting relationship between service effectiveness, cost efficiency and vessel emissions. Other scholars have studied the vessel schedule designing problem with the objective of mitigating total fuel consumed (and emissions) by considering the relationship between vessel sailing speed and fuel consumption [19]. Lindstad et al. [20] examined different effects related to lowering ship speed to understand various impacts on maritime transportation costs and greenhouse gas emissions. Meanwhile, Psaraftis et al. [21] studied the optimization of vessel speed for different routing scenarios and provided useful insights regarding balanced environmental and economic performance of shipping logistics. Several researches have been carried out by considering the slow steaming strategy yet majority of the works overlooked the need to integrate the slow steaming policy with ship routing and scheduling problem for estimating the fuel consumption on different sailing legs while designing the vessel routes. 


\subsection{SHIP ROUTING AND SCHEDULING}

Vessel speed reduction increases the sailing time of ships between different ports, thereby leading to a higher transportation cost for the shipping company. Hence, it is necessary to address the possible ways of improving the service level and simultaneously reducing the voyage cost of the vessel. The routes of each ship should be designed to satisfy the demand at different ports, to lower the transportation cost and to maximise the total revenue generated by the shipping company. Several researchers have studied routing and scheduling problems for maritime logistics companies with the aim of reducing the transportation cost [22]. They have addressed the complexities associated with the designing of vessel routes and their schedules within a particular planning horizon and have presented a mathematical formulation accordingly. Figure 1 shows an example of a ship routing and scheduling network including three ships and seven ports for a specific planning horizon. The first ship starts its journey from port 1 in time period 1 and sails to port 2, reaching there within time period 2. It sails from port 2 and arrives at port 3 in time period 4, and later ends its route at port 1 in time period 5. Routes corresponding to vessels 2 and 3 are mentioned in the figure. Grønhaug et al. [23] and Ronen [24] dealt with ship routing problems for a discrete planning horizon and accordingly presented their mathematical formulations. Siswanto et al. [25] investigated ship routing and scheduling problems, focusing on vessel route selection and loading/unloading operations at port. They addressed the complex issue of meeting the demand for different non-mixable liquid products at various ports. In the context of Liquefied Natural Gas (LNG) distribution, several authors have studied the problem of routing and scheduling of vessels and have presented optimal schedules within the planning horizon [26], [27]. Stålhane et al. [28] investigated a maritime pickup and delivery problem and presented a path-flow formulation to maximise the revenue earned and mitigate the overall travelling cost. Agra et al. [29] dealt with a ship routing problem for distribution of fuel oil products to several loading and unloading ports and accordingly presented a mixed integer formulation. In the context of shipping logistics, other researchers have dealt with real-life case studies of oil companies and have developed mathematical models capturing the intricacies associated with the designing of routes and schedules of vessels between different ports [30]. The time window concept is considered in their work to improve the service level and to minimise the cost related to service time. 

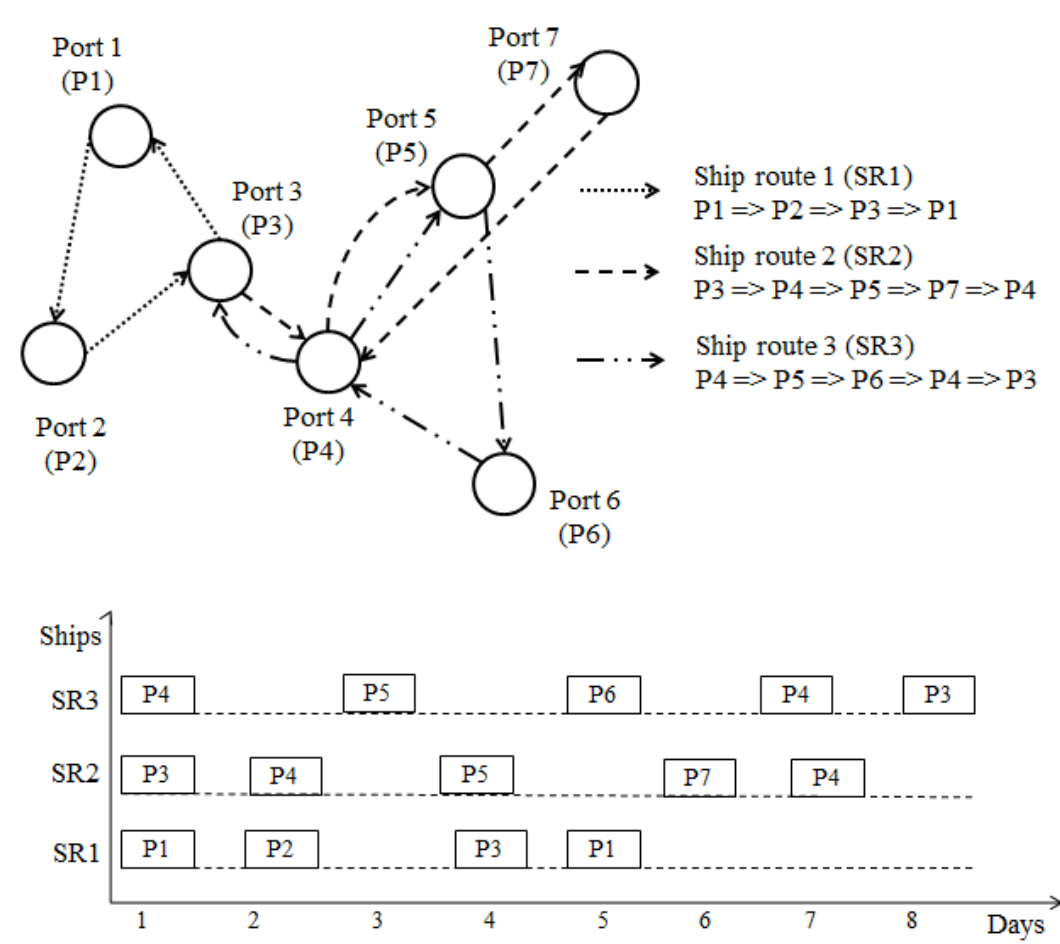

Figure 1: Shipping network with three ships routes in overall planning horizon

\subsection{TIME WINDOW CONCEPT}

Each port has a particular time window for providing services to each containership. Deciding upon an appropriate time window to perform the loading/unloading operations is one of the most complex issues within the ship routing and scheduling domain. A time window exists for each period (day) and its corresponding timings (start and end of the time window) may vary for different ports. A ship arriving early at a port has to wait until the start of the time window to initiate its operations. Sometimes, the port operations of a vessel finish after the completion of the time window, thereby violating the time window. Agra et al. [29] considered the time window concept in their model and incorporated certain penalty charges per hour to deal with violations of the time window. However, their model did not consider the waiting time before the start of the time window for ships arriving early. Figure 2 illustrates the concept of the time window for two different scenarios. Several pieces of research have been carried out to improve the service level at ports by taking into consideration a penalty charge for operation not finishing within the time window [22], [31] and [32]. It is essential to incorporate certain measures to reduce the waiting time and time spent outside the time window. Penalty charges are incurred if the vessel arrives early, before the start of the time window. If a ship fails to finish its operations within the port's working hours, then a demurrage charge is imposed on the number of hours operated after the completion of the time window. More robust ship schedules consider penalties to avoid waiting times due to certain unexpected delays. Fagerholt [33] studied a pickup and delivery problem encountered by multiple vessels and incorporated the time window concept. The strict time windows are relaxed by including certain penalty charges to counter the violation of the time window. Other authors have integrated the time window concept in a short sea inventory routing problem and presented a mathematical formulation considering several 
real-time constraints, capturing the intricacies associated with the time window [30]. Armas et al. [34] introduced a routing and scheduling problem for shipping logistics and incorporated the discretized time window concept. The majority of researchers have overlooked the relationship between high tidal condition and the arrival and departure time of the vessel while considering the time window concept at a port.
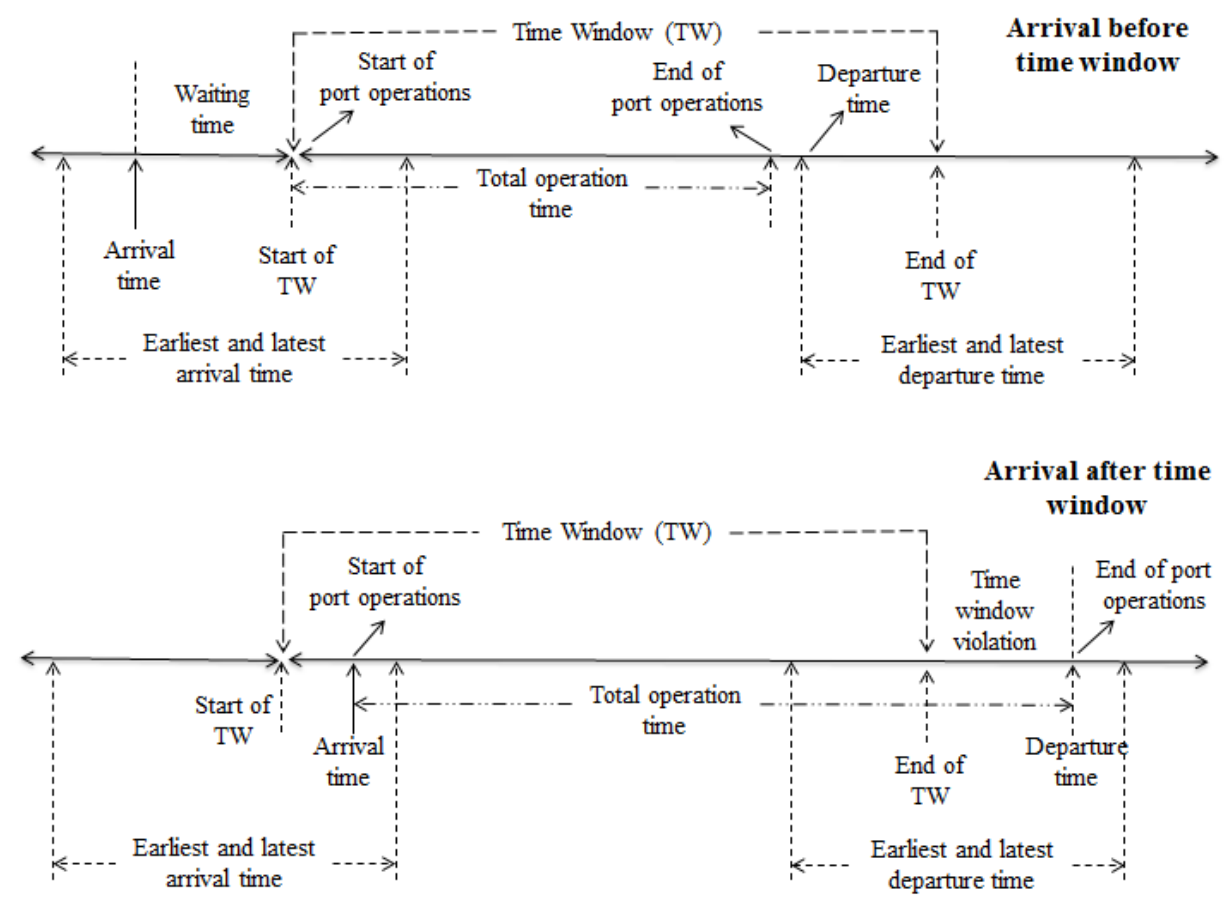

Figure 2: Time window at port: waiting time, operating time inside and outside

\subsection{SHIP'S DRAFT RESTRICTIONS}

In maritime logistics, decisions related to ship routing and scheduling are affected by a vessel's draft restrictions. Rakke et al. [35] dealt with the travelling salesman problem with regard to draft restrictions and proposed two mathematical models for determining the optimal sequence of port visits. A ship's draft restrictions play a significant role in maritime transportation as it determines the number of containers to be loaded onto the vessel. A ship's draft is the distance between the bottom of the vessel and the waterline, and each port has specific safety limits associated with the draft of each ship to reduce the risk of a vessel with deep-draft running in shallow water. As a result, draft restrictions prevent vessels from entering certain ports fully loaded and may affect the sequence of port visits made by a ship. Figure 3 depicts the factors influencing the under-keel clearance of a vessel. Some of the important factors determining the draft of a ship are the depth of the water, tide height at a particular time in a port, ship squat, and the stability of the vessel and its safety margin. Ship squat effect is a phenomenon caused when a ship moves quickly through shallow water. As a result, it creates an area of low pressure in the water causing the vessel to be closer to the seabed. Vessel stability depends upon heel, wave response and wind strength. The heel is an effect of leaning of the ship under the influence of wave or wind strength causing the ship to sit lower in the water, thereby decreasing the under-keel clearance. Ports have certain 
additional safety margins that restrict ships to travel with a high draft through the water. Furman et al. [36] developed a mathematical model considering different draft restrictions for various load and discharge ports. Draft restrictions played an interesting role in their optimization problem as these affect the number of products to be loaded or unloaded. Battarra et al. [37] dealt with the traveling salesman problem in the context of maritime transportation, taking into account draft restrictions. They proposed an exact algorithm based on three mathematical models and compared the performances.

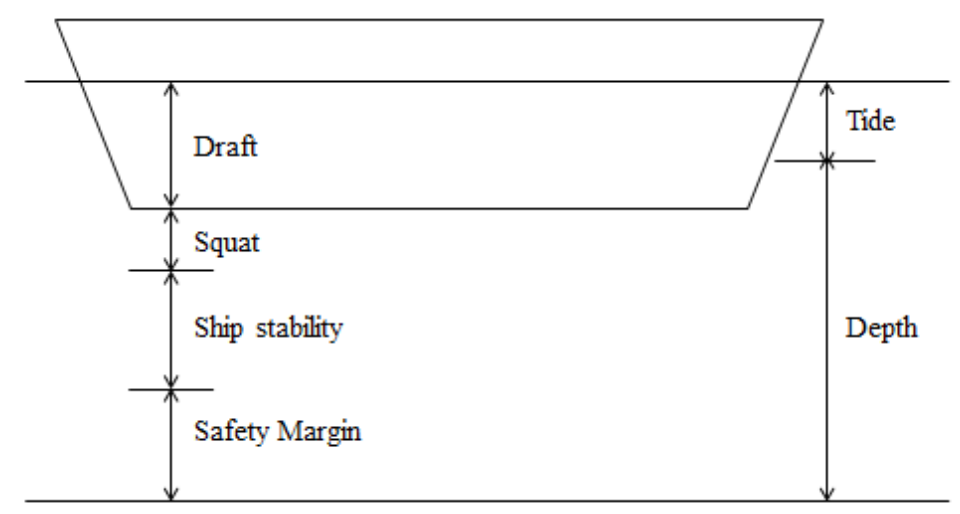

Figure 3: Factors affecting the under-keel clearance of a ship

Several researchers have integrated the time window concept into numerous problems associated with routing and scheduling of vessels but have overlooked the importance of sustainability aspects and vessels' draft restrictions [28], [29], [30], [34]. The time window concept is considered in some of the earlier research to improve the service level of a port by imposing penalty charges when a vessel fails to finish its operations within the allotted time window. Although penalizing vessels for early arrival is essential, the majority of researchers including Agra et al. [29] and De et al. [32] did not consider this in the maritime transportation domain. Multiple vessels arriving before their time window increases congestion and hampers the service level of a port. With this in mind, several measures are incorporated in this research to tackle the early arrival of vessels. Some of the researchers have employed a slow steaming policy in maritime transportation to reduce the total fuel consumption and fuel cost of shipping companies [10], [11], [13]. They have focused primarily on computing bunkering fuel consumption, neglecting the impact of carbon emissions. Kontovas et al. [5] addressed the significance of carbon emissions and presented different mathematical equations to realise the same. In the context of maritime transportation, few researchers have considered a ship's draft restrictions with regard to the travelling salesman problem to ensure safety at a port [35], [37]. However, earlier research works did not capture the complexities associated with routing and scheduling in maritime transportation and also overlooked the significance of addressing sustainability aspects in shipping operations. The contribution of this paper lies in incorporating different real-time and practical maritime operations such as ship routing and scheduling, loading/unloading operations, the time window concept at a port, vessel draft restrictions and carbon emissions. The majority of the research in this domain has considered these issues in isolation in their 
model and has not taken into account the aforementioned shipping operations in a single mathematical model.

\section{PROBLEM DESCRIPTION and MATHEMATICAL MODEL}

\subsection{PROBLEM DESCRIPTION}

Global shipping companies plan vessels' routes and schedules in a particular planning horizon to reduce the overall transportation cost. Ships carry containerized cargo from one port to another to meet the demand in a given period. The planning horizon taken into account comprises of a number of days, referred to as time periods. Each vessel follows its designated trade route comprising many loading and unloading ports. Figure 4 illustrates an example of a trade route of a ship in a planning horizon. Each vessel starts from its initial port at the commencement of the planning horizon and visits several ports in different periods. In the example given, the vessel begins its journey from a particular port in period 1 and visits different ports and finally terminates its route in period 6 . The vessel starts its voyage in period 1 and reaches the next port in period 2. Once the ship finishes its operations, it sails to the next port and reaches it in period 4. The ship then departs from the port in period 4 and finally arrives at the final port of its journey in period 6. The example covers a planning horizon of six periods (corresponding to days) to illustrate the concept of the planning horizon within ship routing and scheduling. Multiple vessels can perform their loading or unloading operations depending on the number of berths available. Port operations are carried out within a specific time window to improve the service level of each port. Different ports have different time window restrictions depending upon the man-power and quay cranes available to implement the loading or unloading operations of containerized cargo. A ship arriving early at a port before the initiation of the time window has to wait until the start of the time window to begin its operations. Penalty charges are incurred per hour for arriving before the start of the time window. The vessel owner is also penalised, if the vessel fails to finish its operations within the time window. Such demurrage charges per hour associated with the violation of the time window increase the total operation cost. Hence, it is essential to design schedules for ships in a way that minimises the overall penalty cost.

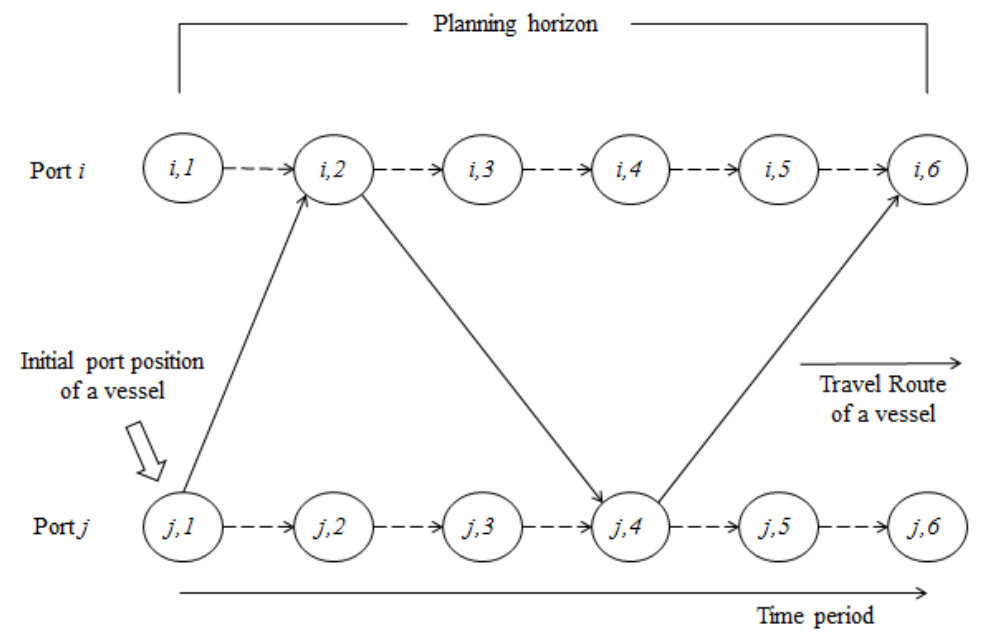


Figure 4: Trade route for a vessel within a planning horizon.

Decisions pertaining to the routing and scheduling of vessels are affected by the ship's draft restrictions as these determine the total tonnage of containerized cargo carried by a vessel entering a certain port. A ship's draft refers to the vertical distance between the surface of the water and the lowest point of the vessel. The draft helps to determine the minimum depth of water that a vessel can safely navigate through and also addresses the risks associated with a deep-draft vessel sailing in shallow water during low tide. Considering draft restrictions in ship routing and scheduling helps to determine the number of containers carried by the ship in terms of the vessel's draft limit and tonnage of containerized cargo per centimetre of draft. Draft restrictions also prevent fully loaded vessels from visiting certain ports during a given time period, thereby reducing risk and improving the safety of the vessel. A ship enters or exits a port through the lock gate only during high tide for reasons of safety. Apart from a ship's draft restrictions, carbon emissions issues and the slow steaming policy are incorporated to address sustainability aspects and to determine the total fuel consumption of a vessel. As mentioned in Yao et al. [10], the amount of fuel consumed by a vessel depends on the ship's sailing speed. The relationship between vessel speed and fuel consumption is considered to estimate the total fuel consumed while travelling from one port to another. Heavy Fuel Oil (HFO) is used to run the main engine of a ship while sailing in the sea and the auxiliary engine runs on Marine Diesel Oil (MDO) while the vessel performs its operations at a port. Carbon emissions are computed for both scenarios by considering the appropriate carbon emissions coefficients for different types of fuels used. The problem is formulated as a Mixed Integer non-Linear Programming (MINLP) model and is presented in the next section, capturing several interactive variables and real-time constraints.

\subsection{MATHEMATICAL MODEL}

The mathematical formulation for the problem described in section 3.1 is considered for a planning horizon of equal intervals/ periods (equivalent to days). Different variables are taken into account to assess the current status of each ship. The mathematical model takes into account the following:

1. Available berth at each port for every period is known.

2. Demand associated with each port is known.

3. Container loading/unloading time is constant.

4. Numbers of available berths at each port in every time-period is fixed.

5. Carbon emission coefficients related to Heavy Fuel Oil (HFO) and Marine Diesel Oil (MDO) are considered for estimating the total carbon emitted.

6. The initial port position of each vessel is known.

7. Fuel consumed (per hour) at a port by the auxiliary engine of the ship is constant.

8. Either loading or unloading operation can be performed at a particular port.

We use the following indices in our mathematical model

$v \quad$ Vessels

$i, j \quad$ Ports 
$t, s \quad$ Time period

Sets

$V \quad$ Set of vessels

$J \quad$ Set of ports

$T \quad$ Set of time periods

Various parameters used in our mathematical model are described as follows:

$C_{i t}^{S} \quad$ Penalty cost (per hour) for waiting at port $i$ before the starting of the time window in period $t$

$C_{i t}^{F} \quad$ Fixed cost for performing loading/unloading operation at port $i$ in period $t$

$C_{i t}^{E} \quad$ Penalty cost (per hour) incurred at port $i$ for operating after the completion of the time window in period $t$

$i_{v} \quad$ Initial port position for vessel $v$

$f_{v i} \quad$ Fuel consumption at port $i$ for vessel $v$ (in tonnes per hour)

$E_{\mathrm{CO}_{2}}^{\mathrm{Sea}} \quad$ Carbon emission coefficient (Tonne of $\mathrm{CO}_{2} /$ Tonne of fuel) at sea

$E_{\mathrm{CO}_{2}}^{\mathrm{Port}_{2}}$ Carbon emission coefficient (Tonne of $\mathrm{CO}_{2} /$ Tonne of fuel) at port

$E_{\text {Fuel }}^{\text {Sea }} \quad$ Fuel price associated with Heavy Fuel Oil (USD/Tonne of fuel)

$B_{i t}^{S} \quad$ Start of time window at port $i$ in period $t$

$B_{i t}^{E} \quad$ End of time window at port $i$ in period $t$

$A_{v i t} \quad$ Expected arrival time at port $i$ for vessel $v$ in period $t$

$\underline{a_{v i t}}, \overline{a_{v i t}}$ Earliest and latest arrival times of vessel $v$ depending upon the high tide scenario at port $i$ in period $t$

$d_{v i t}, \overline{d_{v i t}}$ Earliest and latest departure time of vessel $v$ depending upon the high tide scenario at port $i$ in period $t$

$L_{i j} \quad$ Distance between port $i$ and $j$

$\delta_{i j v}, \overline{\delta_{i j v}} \quad$ Speed range for $\operatorname{ship} v$ while sailing from port $i$ to port $j$

$\theta_{i} \quad$ Number of berths available at port $i$

$D_{v}^{\text {Empty }} \quad$ Draft limit for vessel $v$ sailing empty

$G_{v} \quad$ Tonnage of containerized cargo per centimetre of draft for vessel $v$

$R \quad$ Revenue generated (USD per tonne of containerized cargo)

$\alpha_{i t} \quad$ Tide height at port $i$ in period $t$

$\beta_{i t} \quad$ Depth of water at port $i$ in period $t$

$n_{v i t} \quad$ Squat associated with $\operatorname{ship} v$ at port $i$ in period $t$

$w_{v i t} \quad$ Stability of $\operatorname{ship} v$ depending upon heel and wave response at port $i$ in period $t$ 
$S F_{v i t} \quad$ Safety factor for vessel $v$ at port $i$ in period $t$

$h \quad$ Hours in a day

$P_{i} \quad$ Demand of containerized cargo at port $i$

$S_{i} \quad$ Supply of containerized cargo at port $i$

$Q_{v} \quad$ Maximum capacity (in terms of tonnage of containerized cargo) of vessel $v$

$\tau_{i} \quad=1$, if port $i$ is a supplier of containerized cargo

$=-1$, if the port $i$ has a demand of the containerised cargo

We use the following decision variables in our mathematical model

$F_{i t j s v} \quad$ Fuel consumption (in tonnes per nautical mile) associated with vessel $v$ sailing from port $i$ in period $t$ to port $j$ in period $s$

$z_{v i t} \quad=1$, if a ship $v$ terminates its voyage at port $i$ in period $t$

$=0$, otherwise

$x_{i t j s v} \quad=1$, if $\operatorname{ship} v$ operating at port $i$ in period $t$ travels from port $i$ in period $t$ to port $j$ in period $s$

$=0$, otherwise;

$K_{v i t} \quad$ Tonnage of containerized cargo loaded/unloaded at port $i$ from vessel $v$ in period $t$

$D_{v i t}$ Maximum allowable draft limit at port $i$ for vessel $v$ in period $t, D_{v i t}=0$, for $O_{v i t}=0$

$a_{v i t} \quad$ Arrival time of ship $v$ at port $i$ in period $t$

$d_{v i t} \quad$ Departure time at port $i$ of ship $v$ in period $t$

$e_{v i t} \quad$ Start time of loading/unloading operation for ship $v$ at port $i$ in period $t$

$e_{v i t}^{E} \quad$ End time of the loading/unloading operation for vessel $v$ at port $i$ in period $t$

$\rho_{v i t} \quad$ Total time operated by vessel $v$ outside the time window at port $i$ in period $t$

$\delta_{i t j s v} \quad$ Velocity of vessel $v$ while sailing from port $i$ in period $t$ to port $j$ in period $s$

$M_{v i t} \quad$ Total tonnage of containerized cargo available on ship $v$ while departing from port $i$ after finishing an operation that started in period t, $M_{v i t}=0$ for $O_{v i t}=0$

$O_{v i t} \quad=1$, if ship $v$ performs loading/unloading operation at port $i$ in period $t$ $=0$, otherwise;

The following describes the objective function developed for the mathematical model. 
$\left.\begin{array}{l}\mathrm{R} \sum_{i \in J} \sum_{v \in V} \sum_{t \in T}\left[\left(D_{v i t}-D_{v}^{E m p t y}\right) O_{v i t} G_{v}\right]-E_{F u e l}^{\text {Sea }} \sum_{i, j \in J} \sum_{t, s \in T} \sum_{v \in V} \frac{L_{i j}}{24 \delta_{i t j s v}} F_{i t j s v} x_{i t j s v} \\ -\sum_{i \in J} \sum_{v \in V} \sum_{t \in T} C_{i t}^{F} O_{v i t}-\sum_{i \in J} \sum_{t \in T} \sum_{v \in V} C_{i t}^{S}\left[\operatorname{Max}\left(0,\left(B_{i t}^{S}-a_{v i t}\right)\right)\right]-\sum_{i \in J} \sum_{t \in T} \sum_{v \in V} C_{i t}^{E} \rho_{v i t}\end{array}\right\}$

Equation (1) represents the first objective function of the mathematical formulation depicting the overall profit incurred for performing different shipping operations within a planning horizon. The objective function comprises of five terms. The first term presents the revenue generated for carrying the tonnage of containerized cargo between different ports. The second term is associated with the fuel cost for the shipping company while operating at sea. The third term provides the total fixed cost for carrying out loading/unloading operations. The fourth term is related to the overall penalty cost for waiting before the start of the time window. The fifth term depicts the penalty cost incurred when the vessel fails to finish its operation within the allotted time window.

Minimize $E_{C O_{2}}^{S e a} \sum_{i, j \in J} \sum_{t, s \in T} \sum_{v \in V} \frac{L_{i j}}{24 \delta_{i t j s v}} F_{i t j s v} x_{i t j s v}+E_{C O_{2}}^{P o r t} \sum_{i \in J} \sum_{t \in T} \sum_{v \in V} f_{v i}\left(d_{v i t}-a_{v i t}\right) O_{v i t}$

Equation (2) presents the second objective function estimating the total carbon emission. The first term computes the total carbon emission released in the air while the vessel is sailing in the sea. The second term computes the total carbon emission incurred from the fleet of ships while operating at the port. We use Carbon emission coefficients for Heavy Fuel Oil (HFO) and Marine Diesel Oil (MDO) as 3.082 and 3.021 respectively as mentioned in Kontovas et al. [5]. The update of International Maritime Organisation (IMO) 2000 study presented at $58^{\text {th }}$ Marine Environment Protection Committee (MEPC) considered the carbon emission coefficients for Heavy Fuel Oil (HFO) and Marine Diesel Oil (MDO) as mentioned above [6]. The carbon emission factors lies within the range of Intergovernmental Panel on Climate Change (IPCC) 2006 guidelines as stated in Buhaug et al. [6].

$$
\begin{array}{ll}
F_{i t j s v}=k_{1} \delta_{i t j s v}^{3}+k_{2}, & \forall i, j \in J, \forall t, s \in T, \forall v \in V \\
\delta_{i j v} \leq \delta_{i t j s v} \leq \overline{\delta_{i j v}}, & \forall i, j \in J, \forall t, s \in T, \forall v \in V \\
\delta_{i t j s v}=0 & \text { for } x_{i t j s v}=0
\end{array}
$$

Equation (3) presents the relationship between fuel consumption and vessel speed for a containership. Yao et al. [10] stated that the value of the coefficients $k_{1}$ and $k_{2}$ are different for different sizes of containerships. For this mathematical model, containership of size 6000 TEU (TEU refers to Twenty-foot Equivalent Units) is considered. A typical medium size of containership of 1000 TEU carries 25000 tons of cargo. So, accordingly tonnage of cargo 
carried by 6000 TEU can be estimated. The value of $k_{1}$ and $k_{2}$ for 6000 TEU containership are 0.007297 and 71.4 respectively [10]. Equation (4) provides the upper and lower bounds of the vessel speed variables. The speed of 6000 TEU containership should lie within the range of 14-24 knots [10]. For certain conditions presented in equation (5), the vessel speed between two corresponding ports is considered to be zero.

$$
\left(\beta_{i t}+\alpha_{i t}-D_{v i t}-n_{v i t}-w_{v i t}-S F_{v i t}\right) O_{v i t} \geq 0, \quad \forall i \in J, \forall v \in V, \forall t \in T
$$

Equation (6) addresses the under-keel clearance (UKC) constraint for a vessel at a port. A ship can be allowed to enter a specified port only if the equation (6) is satisfied. Figure (3) presented in the earlier section illustrates different factors affecting the under-keel clearance of the vessel. The distance between the ship's keel and waterline is referred to as the vessel draft. It is essential to maintain certain safety restrictions for smooth movement of the vessel through the channel at a port. Some of the important factors associated with the safety restrictions at a port are the depth of water, height of tide, vessel squat, ship's draft and stability of the ship. The positive UKC factors include depth of water at a port $\left(\beta_{i t}\right)$ and height of tide $\left(\alpha_{i t}\right)$, and negative UKC factors comprises of the draft of the ship $\left(D_{v i t}\right)$, vessel squat $\left(n_{v i t}\right)$, and stability of the ship $\left(w_{v i t}\right)$. The positive UKC factors should be greater than negative UKC factors by some safety factor $\left(S F_{v i t}\right)$. A vessel squat is the phenomenon associated with the fast moving ships through the water creating a lower pressure, which in turn pulls down the vessel closer to the seabed. Stability of the ship depends upon wave response, wind force and heel of the ship.

$$
\sum_{j \in J} \sum_{s \in T} \sum_{v \in V} x_{j s i t v} \leq \theta_{i} \quad \forall i \in J, \forall t \in T
$$

Equation (7) depicts that for a given time period, the number of vessels performing its loading/unloading operation at a port depends upon the total number of berths available.

$$
\begin{array}{ll}
\sum_{i \in J} \sum_{t \in T} z_{v i t}=1 & \forall v \in V \\
\sum_{j \in J} \sum_{s \in T} x_{j s i t v}-\sum_{j \in J} \sum_{s \in T} x_{i t j s v}-z_{v i t}=0 & \forall i \in J, \forall v \in V, \forall t \in T, t>1,
\end{array}
$$

Constraint (8) ensures that the vessel must end its route at a specific port. Constraint (9) represents the flow conservation constraint.

$$
\begin{array}{ll}
x_{i t j s v}=0 & \text { for } i=j, t \geq s \\
\sum_{j \in J} \sum_{s \in T} x_{i_{v} 1 j s v}+z_{v i_{v} 1}=1, & \forall v \in V
\end{array}
$$

Constraint (10) ensures that the binary variable $x_{i t j s v}$ must be zero for the given conditions. Constraint (11) depicts that a vessel may travel from its initial port to another port or it may end its route at a certain port.

$$
O_{v i t}-\sum_{j \in J} \sum_{s \in T} x_{i t j s v} \leq 0, \quad \forall i \in J, \forall v \in V
$$


Constraint (12) ensures that if a vessel performs its operation at a particular port, then the port must belong to the route of the ship.

$$
\begin{array}{ll}
e_{v i t}-A_{v i t} \geq 0, & \forall i \in J, \forall v \in V, \forall t \in T \\
e_{v i t} \geq a_{v i t}, & \forall i \in J, \forall v \in V, \forall t \in T \\
e_{v i t}^{E} \leq d_{v i t}, & \forall i \in J, \forall v \in V, \forall t \in T \\
\frac{a_{v i t}}{\bar{d}} \leq a_{v i t} \leq \overline{a_{v i t}}, & \forall i \in J, \forall v \in V, \forall t \in T \\
\overline{d_{v i t}} \leq d_{v i t} \leq \overline{d_{v i t}}, & \forall i \in J, \forall v \in V, \forall t \in T \\
B_{i t}^{s} \leq e_{v i t} \leq B_{i t}^{E}, & \forall i \in J, \forall v \in V, \forall t \in T
\end{array}
$$

Constraint (13) ensures that the vessel must start its operation at a port after its expected arrival time. Constraint (14a) guarantees that a ship must arrive at the port before the commencement of its loading/unloading operation. Constraint (14b) ensures that the vessel must depart from the port only after finishing its operation. The time interval within which the ship is expected to arrive and depart is given by constraint (15a) and (15b) respectively. Constraint (16) presents the time window range.

$$
\left(d_{v i t}+\frac{L_{i j}}{\delta_{i t j s v}}-h-a_{v j t}\right) x_{i t j s v} \leq 0, \quad \forall i, j \in J, \forall t, s \in T, \forall v \in V
$$

Constraint (17) depicts the relationship between arrival time of the vessel at a port with the departure time of the ship from previous port and the sailing time between two ports.

$$
\begin{array}{ll}
\rho_{v i t}-e_{v i t}^{E}+B_{v i t}^{E} \geq 0, & \forall i \in J, \forall v \in V, \forall t \in T \\
e_{v i t}-e_{v i(t-1)}^{E} \geq 0, & \forall i \in J, \forall v \in V, \forall t \in T, i>1
\end{array}
$$

The penalty cost incurred for operation outside the time window is realized using constraint (18). Equation (19) represents the scenario of a vessel starting its port operation in a given period only after it finishes its operation in the previous period.

$$
\begin{array}{ll}
x_{i t j v}\left(M_{v i t}+\tau_{j} K_{v j s}-M_{v j s}\right)=0, & \forall i, j \in J, \forall t, s \in T, \forall v \in V \\
K_{v i t} \leq Q_{v} O_{v i t} & \forall i \in J, \forall v \in V, \forall t \in T \\
M_{v i t} \leq Q_{v} \sum_{j \in J} \sum_{s \in T} x_{i t j s v}, & \forall i \in J, \forall t \in T, \forall v \in V \\
P_{i}+\sum_{v \in V} \sum_{t \in T} K_{v i t} \tau_{i} \geq 0 & \forall i \in J, \tau_{i}=-1 \\
S_{i}-\sum_{v \in V} \sum_{t \in T} K_{v i t} \tau_{i} \geq 0 & \forall i \in J, \tau_{i}=1
\end{array}
$$


Equation (20) states that the number of containers on a vessel while leaving a particular port plus the number of container loaded/unloaded on the next port should be equal to the number containers on vessel while departing from the second port. Equation (21) depicts that the number of containers loaded/unloaded should be less than the maximum capacity of the vessel. Upper bound on the number of containers loaded/unloaded is given by the equation. Equation (22) presents the upper bound of the total number of containers carried by the vessel. Equation (23a) and (23b) makes sure that the demand and supply of containerized cargo at each port is satisfied.

$$
\begin{array}{ll}
x_{i t j s v} \in\{0,1\}, & \forall i, j \in J, i \neq j, \forall t, s \in T, t \neq s, \forall v \in V \\
z_{v i t} \in\{0,1\}, & \forall i \in J, \forall v \in V, \forall t \in T \\
O_{v i t} \in\{0,1\}, & \forall i \in J, \forall v \in V, \forall t \in T \\
e_{v i t}, e_{v i t}^{E}, \rho_{v i t}, a_{v i t}, d_{v i t} \geq 0, & \forall i \in J, \forall v \in V, \forall t \in T \\
F_{i t j s v}, \delta_{i t j s v} \geq 0, & \forall i, j \in J, \forall t, s \in T, i \neq j, \forall v \in V
\end{array}
$$

Equations (24), (25) and (26) represent the binary variables. Equations (27) and (28) represent the non-negativity constraints.

Equation (20) can be linearized as mentioned in Al-Khayyal et al. [22] and Agra et al. [29]. Therefore, equation (20) can be replaced with the following sets of equations,

$$
\begin{array}{ll}
M_{v i t}+\tau_{j} K_{v j s}-M_{v j s}+Q_{v} x_{i t j s v} \leq Q_{v}, & \forall i, j \in J, \forall t, s \in T, \forall v \in V \\
M_{v i t}+\tau_{j} K_{v j s}-M_{v j s}-Q_{v} x_{i t j s v} \geq-Q_{v}, & \forall i, j \in J, \forall t, s \in T, \forall v \in V
\end{array}
$$

Now, equation (31) presents the number of containers carried by the vessel from a specific port in a given time period.

$$
M_{v i t}=\left(D_{v i t}-D_{v}^{\text {Empty }}\right) G_{v}
$$

The number of containers carried by the ship can be expressed in terms of the maximum allowable draft limit of the vessel and tonnage of containerized cargo per centimetre of the draft of the ship.

Therefore, using equation (31), equations (29) and (30) can be restructured in the following ways,

$\left(D_{v i t}-D_{v}^{E m p t y}\right) G_{v}+\tau_{j} K_{v j s}-\left(D_{v j s}-D_{v}^{E m p t y}\right) G_{v}+Q_{v} x_{i t j s} \leq Q_{v}$

or, $D_{v i t} G_{v}-D_{v}^{E m p t y} G_{v}+\tau_{j} K_{v j s}-D_{v j s} G_{v}+D_{v}^{E m p t y} G_{v}+Q_{v} x_{i t j s v} \leq Q_{v}$

or, $D_{v i t} G_{v}+\tau_{j} K_{v j s}-D_{v j s} G_{v}+Q_{v} x_{i t j s v} \leq Q_{v} \quad \forall i, j \in J, \forall t, s \in T, \forall v \in V$

Similarly, equations (33) and (34) can be obtained using equations (30), (31) and equations (31), (22) respectively,

$$
\begin{array}{ll}
D_{v i t} G_{v}+\tau_{j} K_{v j s}-D_{v j s} G_{v}-Q_{v} x_{i t j s v} \geq-Q_{v} & \forall i, j \in J, \forall t, s \in T, \forall v \in V \\
\left(D_{v i t}-D_{v}^{E m p t y}\right) G_{v} \leq Q_{v} \sum_{j \in J} \sum_{s \in T} x_{i t j s v}, & \forall i \in J, \forall t \in T, \forall v \in V \\
D_{v i t} \geq 0, & \forall i \in J, \forall t \in T, \forall v \in V \\
K_{v i t}, M_{v i t} \geq 0 & \forall i \in J, \forall t \in T, \forall v \in V
\end{array}
$$

Equation (35) and (36) represents the non-negativity constraints. 
The mathematical formulation comprises of two objective functions presented in equations (1) and (2). The constraints are depicted in equations (3) - (19), (21), (23a), (23b), (24) (28), (32), (33) (34), (35) and (36). The mathematical model presented in this section consists of different variables associated with loading/unloading operations, ship routing and scheduling, vessel speed, time window concept and ship's draft restriction. For such a complex mathematical formulation, the number of continuous and binary variables as well as equality and inequality constraints increases exponentially for every problem instances considered for computational experiment purpose. Computational efficiency for solving such a complicated problem deteriorates for every test case. Research work of Mirhassani et al. [38] and Repoussis et al. [39] stated that an exact heuristic takes a long and unrealistic time to solve even a moderate sized problem. Moreover, they mentioned that the limitation of operations research based solvers to solve a medium size problem instance. Therefore, it is essential to apply evolutionary algorithms such as the one used in this research including NSGA-II (non-dominated sorting genetic algorithm II) and MOPSO (multi-objective particle swarm optimization) to deal with the computational complexity of multi-objective problem in this research.

\section{SOLUTION METHODOLOGY}

With an increasing number of time periods, ships and ports, the number of decision variables and constraints for a mathematical model also escalates, and the computational complexity in solving such a problem becomes time-consuming. Such a multi-objective mathematical model requires meta-heuristic techniques to solve large problems and to obtain a near-optimal solution. Two multi-objective techniques - Non-Dominated Sorting Genetic Algorithm II (NSGA-II) and Multi-Objective Particle Swarm Optimization (MOPSO) - are employed to solve the aforesaid mathematical formulation.

\subsection{INITIAL SOLUTION}

NSGA-II and MOPSO algorithms need to generate an initial solution to initiate their respective searching procedures. The initial solution comprises all of the independent and dependent variables associated with the mathematical model. The problem mentioned above consists of different types of variables depicting the time window concept, ship routing and scheduling, vessel speed and loading/unloading operations. The initial feasible solution is generated considering different sets of constraints given in the mathematical formulation and assessing the interaction between dependent and independent variables. The values of the routing variables $x_{i t j s v}$ and $z_{v i t}$ are generated by satisfying equations (7) and (8) respectively. The feasibility of the values obtained is validated using equation (9) representing the flow conservation constraint. Infeasible values are discarded and feasible values of the binary variables are stored for further processes. The vessel speed variables are generated within a range of 14-24 knots as mentioned in Yao et al. [10] for 6000 TEU containerships.

The value of $\delta_{i t j s v}$ is assumed to be zero when the routing variable $x_{i t j s v}$ takes the value zero as mentioned in equation (5). The value obtained for the vessel speed is fed into equation (3) to estimate the fuel consumed by each vessel while sailing between the two ports. 
Loading/unloading variable $O_{v i t}$ is calculated using equation (12) and the value of routing variable $x_{i t j s v}$. Initially, the value of $M_{v i t}$ is obtained within a given range and later using the value of the binary variable $x_{i t j s v}$ and equation (22), $M_{v i t}$ is updated. If no loading/unloading operation takes place at a particular port in a given period $\left(O_{v i t}=0\right)$, then the value of $M_{v i t}$ for the corresponding port is assigned as zero. The maximum allowable draft limit for a vessel at a particular port, $D_{v i t}$ is computed using the value of $M_{v i t}$ and equation (31). The tonnage of containerized cargo loaded/unloaded from a ship at a specific port $K_{v i t}$ is estimated within a particular range. Considering the binary variable corresponding to the loading/unloading operation and maximum containerized cargo carrying capacity of a vessel (in terms of tonnage), the value of $K_{v i t}$ is updated using equation (21). Starting time of an operation for a ship at a port, $e_{v i t}$ is computed using the range given in equation (16). Arrival time for a vessel at a port, $a_{v i t}$ is estimated within a range presented in equation (15). The feasibility of the decision variables $e_{v i t}$ and $a_{v i t}$ is checked using equation (14) and infeasible values are discarded in this process. Ending time of operation for a certain vessel at a port, $e_{v i t}^{E}$ is computed by using the values of the arrival time of a ship $\left(a_{v i t}\right)$, vessel speed $\left(\delta_{i t j s v}\right)$ and route variables $\left(x_{i t j s v}\right)$ in equation (17). The value of the penalty variable, $\rho_{v i t}$ associated with the violation of the time window for a ship is calculated using equation (18) and the values pertaining to the ending time of the operation for the vessel, $e_{v i t}^{E}$ and the closing time of the time window. Initialization of the solution is presented in a way as mentioned in the literature for different nature of problems such as routing, scheduling, etc. The initial solution generated is fed into each of the algorithms to start their respective procedures.

\subsection{NSGA-II (Non-dominated Sorting Genetic Algorithm II)}

Deb et al. [40] proposed NSGA-II as an effective and efficient multi-objective evolutionary algorithm. Repoussis et al. [39] and Li et al. [41] employed NSGA-II for resolving their respective multiple objective optimization problems. Over the past decades, several algorithms are proposed such as multi-objective genetic algorithm, NSGA, Pareto evolutionary algorithm and NSGA-II, etc. Among all these multi-objective optimization algorithms, NSGA-II is the most efficient algorithm as it provides a better solution with high accuracy and convergence speed on most of the benchmark problems[41-42]. NSGA-II performs better than other existing algorithms in terms of searching a diverse set of solutions and converging near the true Pareto-optimal set [43]. Other researchers compared their proposed multi-objective algorithms with NSGA-II to justify the performance pertaining to solution quality and computational time [44], [45]. Genetic algorithm based meta-heuristic techniques are quite popular among researchers for resolving different combinatorial optimization problems as it provides superior performance when compared with other optimization techniques [49], [50], [51] and [57]. Based on the abovementioned justification, NSGA-II is employed to resolve the proposed mathematical model presented in the preceding section. 
NSGA-II algorithm is comprised of following operators: selection, crossover, mutation, nondominated sorting technique and crowding distance. The algorithm starts with an initial population of chromosomes. All the decision variables present in the mathematical model are properly arranged to form a single chromosome. Figure 5 depicts the basic structure of a chromosome. Non-dominated sorting technique assigns a rank to each chromosome of the population. Figure 6 presents the flowchart of the non-dominated sorting technique. Crowding distance is calculated for each chromosome with the same rank. Figure 7 depicts the pseudo-code for the crowding distance computation algorithm. So, the operators (nondominated sorting and crowding distance) are employed to rank and select the population fronts.

\begin{tabular}{|l|l|l|l|l|l|l|l|l|l|l|}
\hline$x_{i t j s v}$ & $Z_{v i t}$ & $e_{v i t}$ & $e_{v i t}^{E}$ & $\delta_{i t j s v}$ & $\rho_{v i t}$ & $O_{v i t}$ & $K_{v i t}$ & $D_{v i t}$ & $a_{v i t}$ & $d_{v i t}$ \\
\hline
\end{tabular}

Figure 5: Structure of a chromosome consisting of all the variables

Offspring populations are generated after performing the following techniques on the parent population - tournament selection, crossover and mutation. Figure 8 presents the flowchart of the NSGA-II algorithm based on Deb et al. [40]. The population containing the offspring combines with the parent population to form an overall population of $2 \mathrm{~N}$ (population size $=$ $N)$ size. The combined population is presented in different fronts using the non-dominated sorting technique. If the number solution in the first front is less than $\mathrm{N}$, then all the chromosomes present in the first front is added to the new population. If the solutions are not enough, then chromosomes are selected from the second front. If the numbers of individuals accepted from the last front are more than the number required, then the chromosomes present in the front are sorted on the basis of the crowding distance, and exact numbers of individuals required are chosen. The best chromosomes are selected as the solutions on the basis of the diversity and non-dominance. The new population formed is used for selection, crossover and mutation operators.

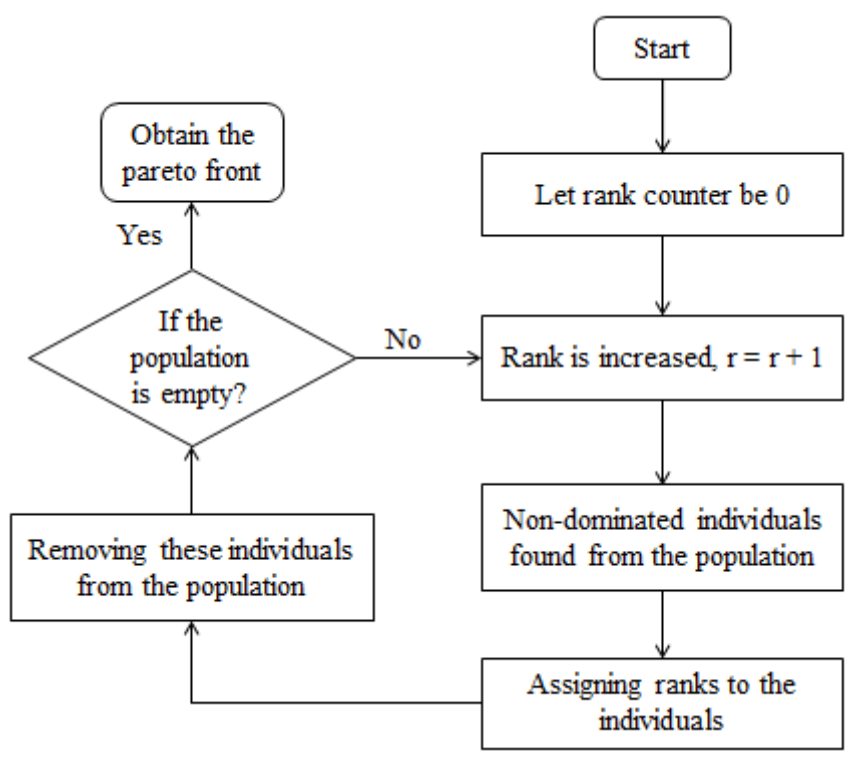

Figure 6: Flowchart of non-dominated sorting technique 


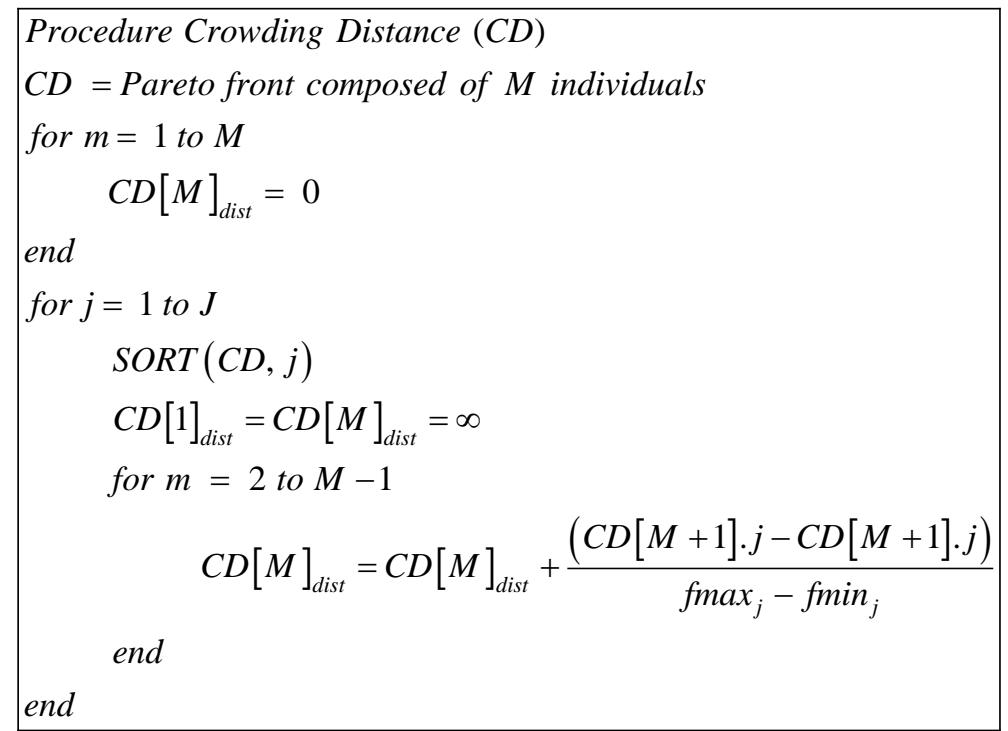

Figure 7: Pseudo code of the crowding distance computation operator

NSGA-II uses the crowded comparison operator to select an individual between two solutions with lesser domination rank when both the individual belong to different fronts. But when both the solutions lie on the same front, then the individual in the less dense region (having higher crowding distance) is preferred over the other. $C D$ refers to a Pareto front comprised of $\mathrm{M}$ individuals. $C D[m] . j$ depicts the $j^{\text {th }}$ objective of the $m^{\text {th }}$ individual in the front $C D$. max $_{j}$ and $\operatorname{fmin}_{j}$ represents the maximum and minimum value of objective $j$. Crowding distance of every individual is initialized to zero. The solutions are sorted in ascending order of their objective value for every objective $j$. Infinite crowding distance value is assigned to all the boundary solutions with minimum and maximum crowding distance.

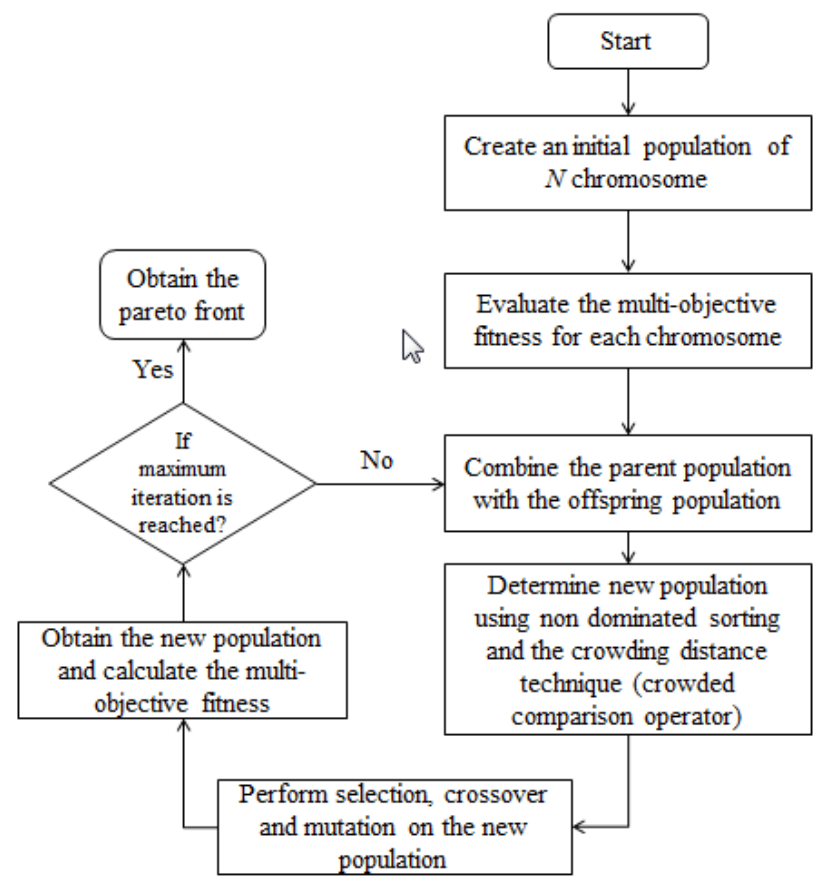




\subsection{MOPSO (Multi-Objective Particle Swarm Optimization)}

Multi-objective particle swarm optimization (MOPSO) algorithm is commonly used in the literature for numerous optimization problems [46], [47] and [48]. Non-dominated Sorting and Crowding Distance techniques presented in the earlier section are also considered in this algorithm. Particle swarm optimization based algorithms are simpler computational calculation than other intelligent search heuristics. Majority of the researchers highlighted the robustness of PSO-based algorithms in adapting to several benchmark problems without changing the values of the algorithmic parameters [46]. Recently, researchers considered MOPSO algorithms due to its straightforward and simplistic concept in resolving computationally intractable optimization problems [46], [47] and [48]. Hence, MOPSO algorithm is used in this research as it provides superior performance than other on-par stochastic optimization methods.

In MOPSO algorithm, the personal best and the global best behaviour of each individual referred to as "particle" help in converging to a near-optimal position. All the particles are together called swarm looks for an optimum solution in the search space. Particle's position is a point in the solution space considering the values of all the attributes present in the problem. Figure 9 provides the swarm representation for the aforementioned mathematical model. A simple example of three ports, three periods and two ships is considered to illustrate the arrangement of 100 particles in the swarm. The decision variables present in the mathematical formulation is organized in the following manner as shown in figure 9.

\begin{tabular}{|c|c|c|c|c|c|c|c|c|c|c|c|}
\hline Particle & $1-162$ & $163-180$ & 181-198 & 199-216 & $217-234$ & $235-252$ & $253-270$ & $271-288$ & $289-306$ & $307-324$ & $325-342$ \\
\hline 1 & $x_{i t j s v}$ & $Z_{v i t}$ & $e_{\text {it }}$ & $e_{v i t}^{E}$ & $\delta_{i t j s v}$ & $\rho_{v i t}$ & $O_{v i t}$ & $K_{v i t}$ & $D_{v i t}$ & $a_{v i t}$ & $d_{v i t}$ \\
\hline 2 & $x_{i t j s v}$ & $Z_{v i t}$ & $e_{\text {it }}$ & $e_{v i t}^{E}$ & $\delta_{i t j s v}$ & $\rho_{\text {vit }}$ & $O_{v i t}$ & $K_{v i t}$ & $D_{\text {vit }}$ & $a_{v i t}$ & $d_{v i t}$ \\
\hline 3 & $x_{i t j s v}$ & $Z_{v i t}$ & $e_{\text {it }}$ & $e_{v i t}^{E}$ & $\delta_{i t j s v}$ & $\rho_{v i t}$ & $O_{v i t}$ & $K_{v i t}$ & $D_{v i t}$ & $a_{v i t}$ & $d_{v i t}$ \\
\hline . & . & . & . & . & . & . & . & . & . & . & \\
\hline & . & . & . & . & . & . & . & . & . & . & \\
\hline & . & . & . & . & . & . & . & . & . & . & \\
\hline 100 & $x_{i t j s v}$ & $Z_{v i t}$ & $e_{\text {it }}$ & $e_{\text {vit }}^{E}$ & $\delta_{i t j s v}$ & $\rho_{v i t}$ & $O_{v i t}$ & $K_{v i t}$ & $D_{v i t}$ & $a_{\text {vit }}$ & $d_{v i t}$ \\
\hline
\end{tabular}

Figure 9: Swarm representation for MOPSO algorithm

Each particle is updated by adding it's velocity in equation (37). Here, $x_{i}^{t}$ denotes the particle $i$ at $t^{\text {th }}$ iteration and $v_{i}^{t}$ represent the velocity of the particle $i$ at $t^{\text {th }}$ iteration.

$x_{i}^{t+1}=x_{i}^{t}+v_{i}^{t}$

The velocity of each particle drives the optimization and considers both social and personal experiences and the particle velocity is updated using equation (38). Here, pbest ${ }_{i}^{t}$ denotes the best personal position of a particle $i$ at $t^{\text {th }}$ iteration and gbest $_{i}^{t}$ represent global best position at 
$t^{\text {th }}$ iteration. $w$ is the inertia weight, $c_{2}$ and $c_{2}$ are the acceleration coefficients, $r_{1}$ and $r_{2}$ are two random vectors in the range $[0,1]$.

$$
v_{i}^{t+1}=w v_{i}^{t}+c_{1} r_{1}\left(\text { pbest }_{i}^{t}-x_{i}^{t}\right)+c_{2} r_{2}\left(\text { gbest }^{t}-x_{i}^{t}\right)
$$

The ranks of the new particles are determined using non-dominated sorting and crowding distance techniques. Here, the newly generated swarm is combined with the earlier swarm. When a maximum number of iteration (convergence criteria) is reached, the algorithm stops and retrieves the Pareto Front. Figure 10 presents the flowchart of MOPSO algorithm.

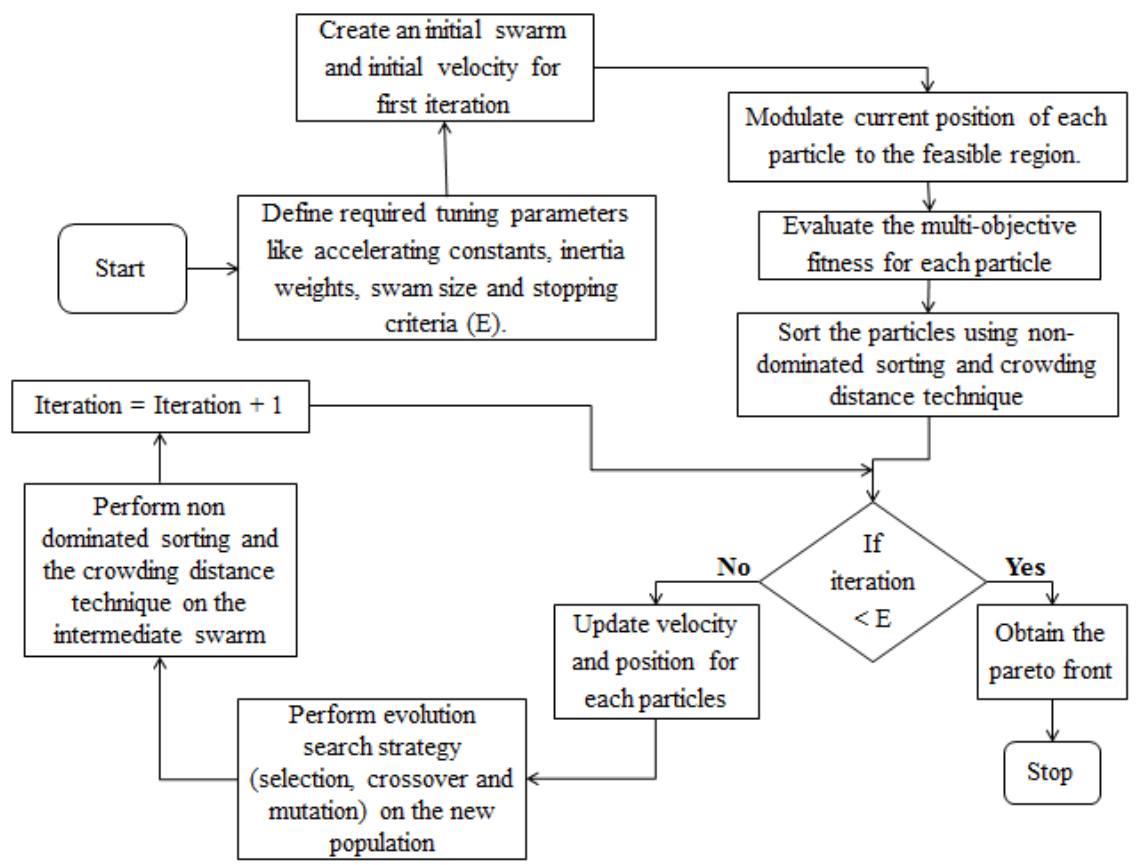

Figure 10: Flowchart of MOPSO algorithm

\section{RESULT AND DISCUSSIONS}

The computational experiments are performed on the problem instances to verify the proposed mathematical model mentioned in the preceding sections. The small, medium and large sized problem instances are developed by varying the number of ports, time periods and ships. Problem instances considered for experimental purposes are designed after taking inspiration from some of the real-world problems encountered by international shipping companies.

\subsection{EXPERIMENTAL SETTINGS}

All of the computational experiments are conducted on MATLAB R2014a software having 8 GB RAM with Intel Core i7 1.8 GHz processor and 64-bit Operating System of Windows 8. Data associated with the model parameters are borrowed from several sources [5], [7], [32], [37], [52], [53] and [56]. NSGA-II and MOPSO are employed to solve and validate all of the problem instances of the aforementioned mathematical model. The best parameters settings pertaining to NSGA-II and MOPSO algorithms for effectively solving the proposed multiobjective model are obtained after performing certain preliminary test runs. The following 
parameters are set for NSGA-II: population size $=200$, crossover rate $=0.80$, mutation rate $=$ 0.70 , and the number of generations $=100$. The parameters of MOPSO are appropriately tuned to obtain near-optimal solutions for each of the problem instances. Values of the parameters of MOPSO are given as: swarm size $=200$, inertia weight $=0.9$, acceleration coefficients $=0.1$ and 0.98 , and number of iterations $=100$.

\subsection{COMPUTATIONAL COMPLEXITY AND EFFICIENCY}

The NSGA - II algorithm examines (population size $\times$ number of generations $=300 \times 100$ $=$ ) 30,000 solutions. Identically, the number of solutions explored by MOPSO is (swarm size $\times$ number of iterations $=300 \times 100=$ ) 30,000 . The performances of both the algorithms are assessed based upon the same number of solutions searched. Table 1 presents five problem instances and highlights their complexities pertaining to the number of constraints and variables evaluated. Table 1 also depicts the computational efficiency required to solve different problem instances using NSGA-II and MOPSO algorithms. Insights are drawn from the table pertaining to the competency of the algorithms regarding the computational time required to solve each of the problem instances. From Table 1, it can be summarised that the computational efficiency of NSGA-II is superior when compared with MOPSO for large problem instances. Dealing with such complexities associated with each of the problem instances and exploration of large number of solutions justifies the robustness of the algorithms.

Table 1: Different problem instances and computational time required to solve them

\begin{tabular}{|c|c|c|c|c|c|}
\hline $\begin{array}{c}\text { Serial } \\
\text { No. }\end{array}$ & $\begin{array}{c}\text { Problem instances } \\
\text { (ports, periods, ships) }\end{array}$ & $\begin{array}{c}\text { Total number } \\
\text { of variables }\end{array}$ & $\begin{array}{c}\text { Total number } \\
\text { of constraints }\end{array}$ & $\begin{array}{c}\text { Computational } \\
\text { time required for } \\
\text { NSGA-II (sec) }\end{array}$ & $\begin{array}{c}\text { Computational } \\
\text { time required for } \\
\text { MOPSO (sec) }\end{array}$ \\
\hline 1 & $(3,3,2)$ & 666 & 766 & 15.30 & 17.87 \\
\hline 2 & $(5,3,3)$ & 2475 & 2766 & 22.35 & 28.93 \\
\hline 3 & $(8,6,4)$ & 29,568 & 30,600 & 168.31 & 232.67 \\
\hline 4 & $(10,8,6)$ & $1,20,000$ & $1,22,392$ & 758.67 & 1065.31 \\
\hline 5 & $(14,10,8)$ & $4,81,600$ & $4,87,384$ & 3395.3 & 4797.7 \\
\hline
\end{tabular}

\subsection{EXPERIMENTAL RESULTS AND SENSITIVITY ANALYSIS}

For all of the problem instances, one of the Pareto solutions pertaining to carbon emissions (incurred in terms of Tonne of $\mathrm{CO}_{2}$ ) and profit (USD) is presented in Table 2. Carbon emissions incurred for problem instance (3-3-2) employing NSGA-II and MOPSO are 1.458 $\times 10^{3}$ Tonne of $\mathrm{CO}_{2}$ and $1.503 \times 10^{3}$ Tonne of $\mathrm{CO}_{2}$ respectively. Figures 11 and 12 present the (3-3-2) problem instance's Pareto front consisting of the non-dominated solutions with ranking 1 and 2 obtained using both the algorithms. Two Pareto fronts are selected based on the ranks, and the best solutions fall under rank 1 while rank 2 contains the second best solutions. Visual illustrations of the Pareto fronts for the problem instance (5-3-3) generated by the algorithms are depicted in figures 13 and 14. Non-dominated solutions presented in the Pareto front preserve both the quality and diversity of the solution. Out of all the non- 
dominated solutions of the problem instance (5-3-3) present in the Pareto front in rank 1, one solution is considered and mentioned in Table 2. The Pareto fronts pertaining to the problem instance (8-6-4) for both the algorithms are illustrated in figures 15 and 16. The figures highlight that excess carbon emissions are incurred when shipping companies look for more profit. Figures 17 and 18 present the points in the final near-optimal Pareto front for the problem instance (10-8-6) when solved using NSGA-II and MOPSO. Figures 19 and 20 provide the Pareto front for both the algorithms pertaining to problem instance (14-10-8). The solutions of the Pareto front relating to problem instances (10-8-6) and (14-10-8) are mentioned in Tables 3 and 4. Pareto front solutions help decision makers to explore different possibilities and find the ideal combination of both objectives according to their requirements. The Pareto front provides diverse solutions with different values associated with both of the objective functions while it also gives the decision maker more options to consider. A sensitivity analysis is performed on three problem instances - $(14,10,8),(10,8,6)$ and $(8,6,4)$ by increasing and decreasing the tonnage of containerized cargo per centimetre of the draft and the values obtained are presented in Table 5. Tonnes of containerized cargo loaded per centimetre of the draft can vary for different ports as this depends upon the density of water in the particular location. It is observed that with the increment or decrement in tonnes of containerized cargo per centimetre of vessel draft, the profit associated with the shipping company increases or decreases. From Table 5, it is also revealed that the carbon emissions remain unchanged for any change in tonnes per centimetre of the draft.

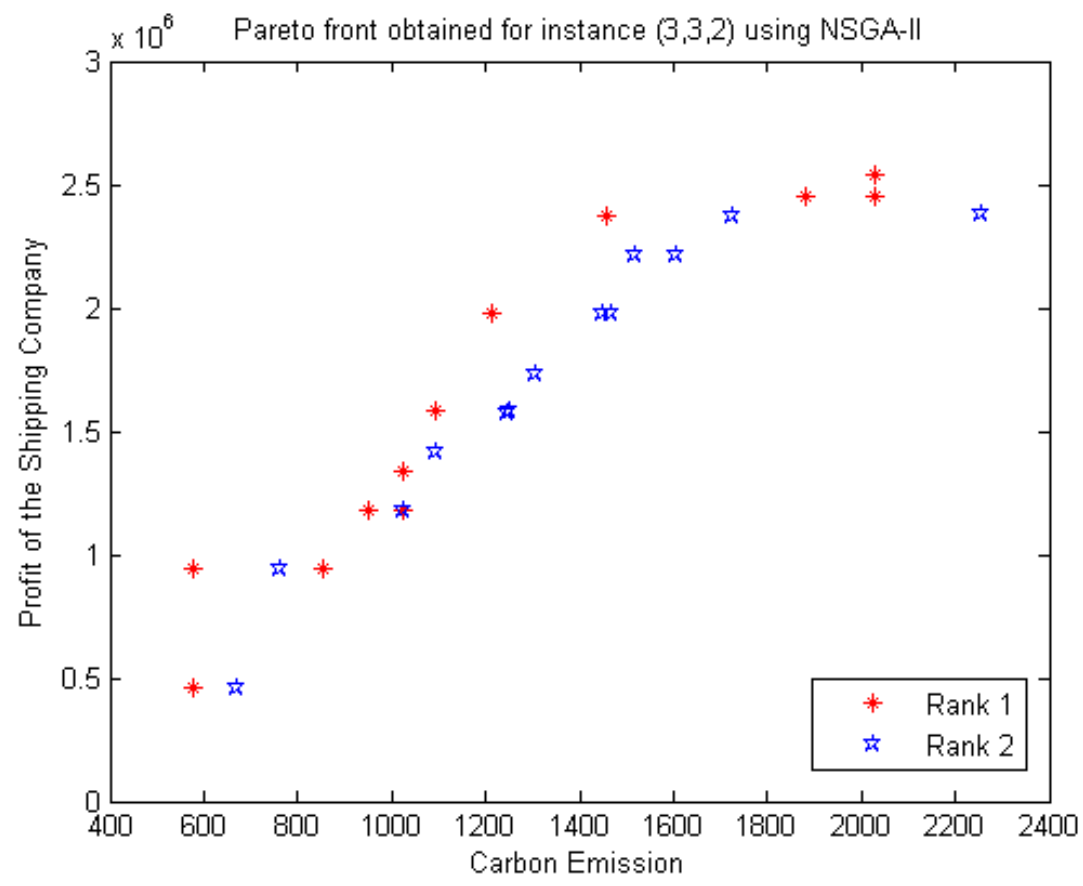

Figure 11: Pareto front generated using NSGA-II for problem instance (3-3-2) 


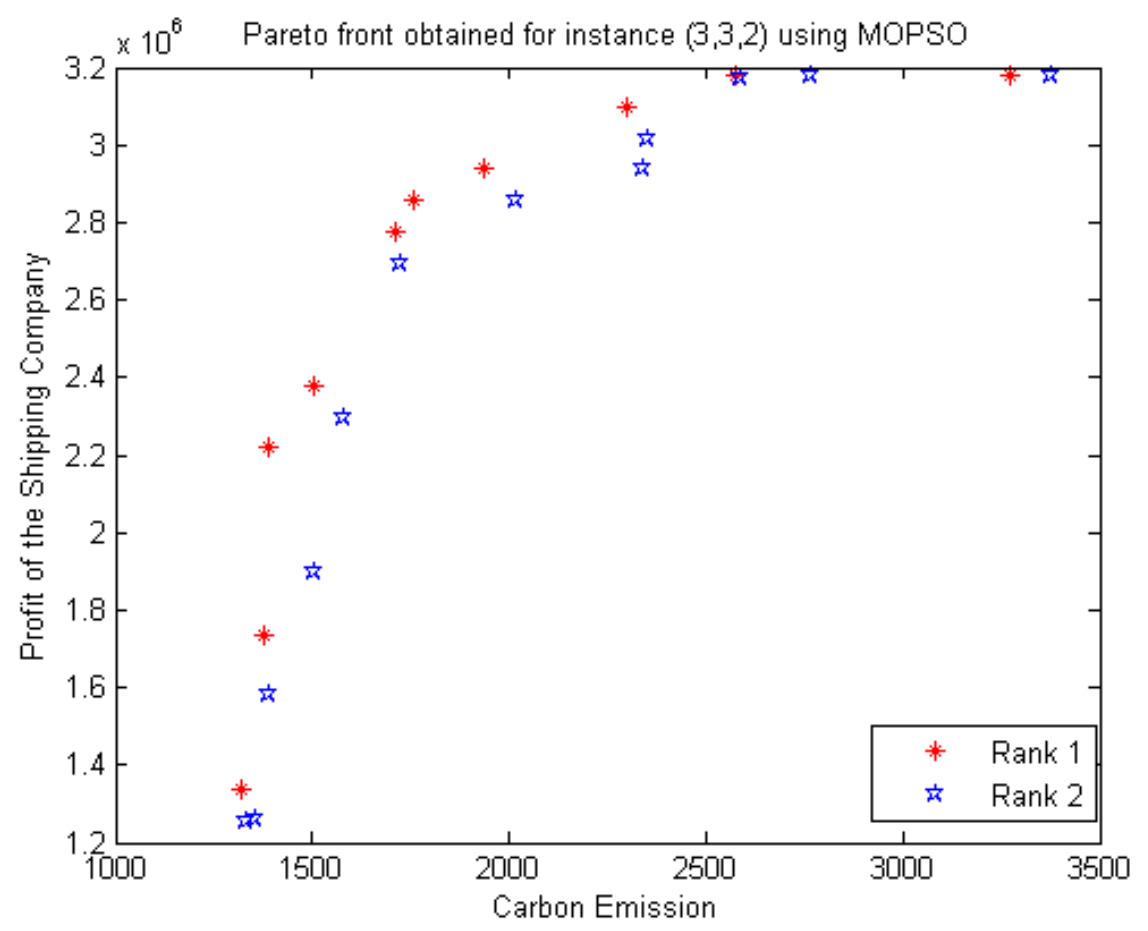

Figure 12: Pareto front generated using MOPSO for problem instance (3-3-2)

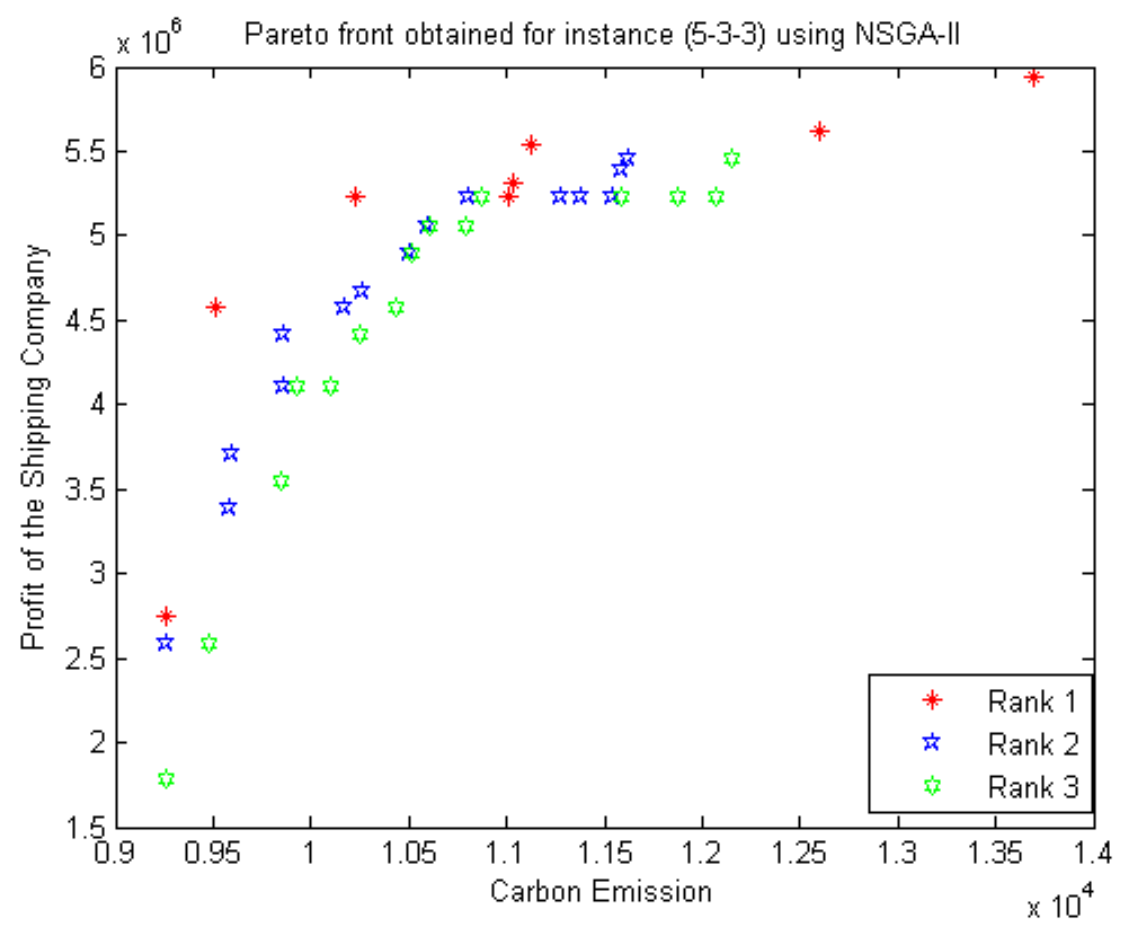

Figure 13: Pareto front generated using NSGA-II for problem instance (5-3-3) 


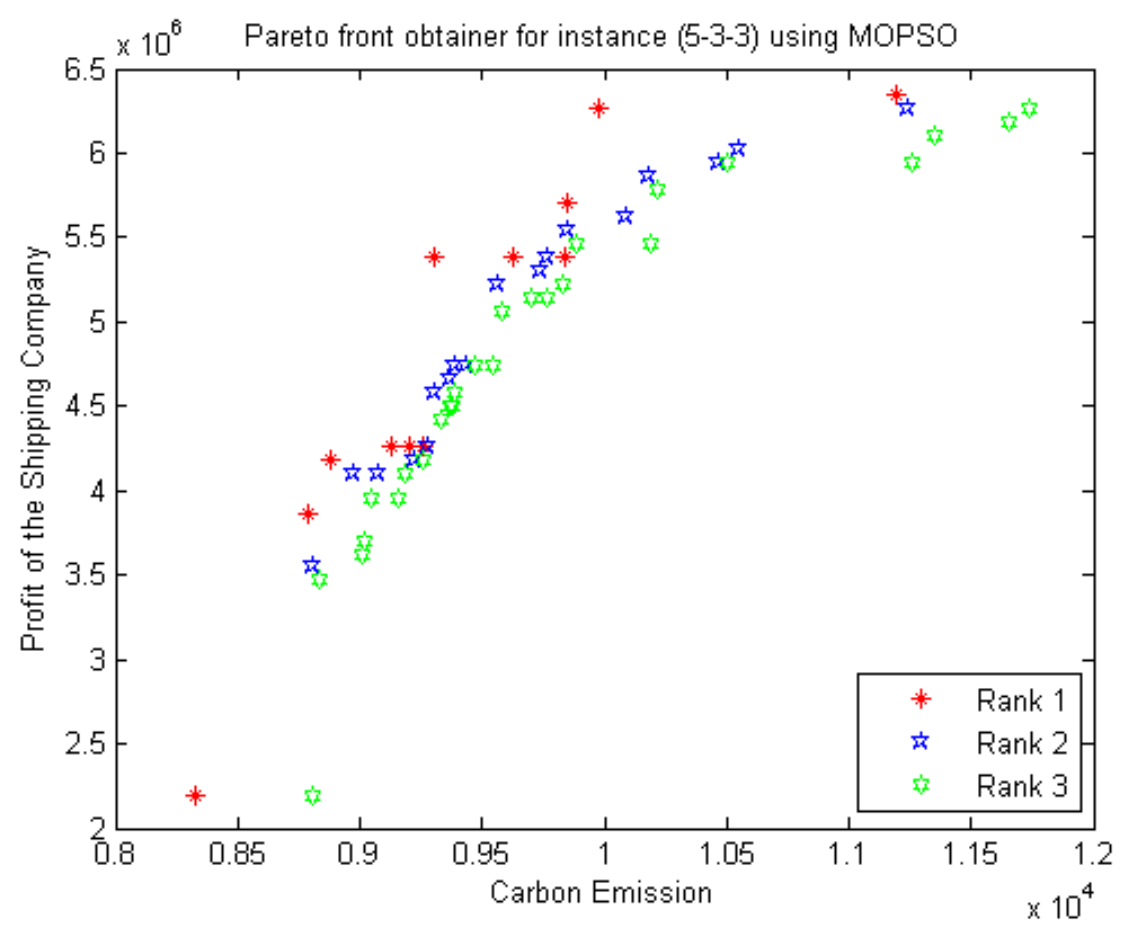

Figure 14: Pareto front generated using MOPSO for problem instance (5-3-3)

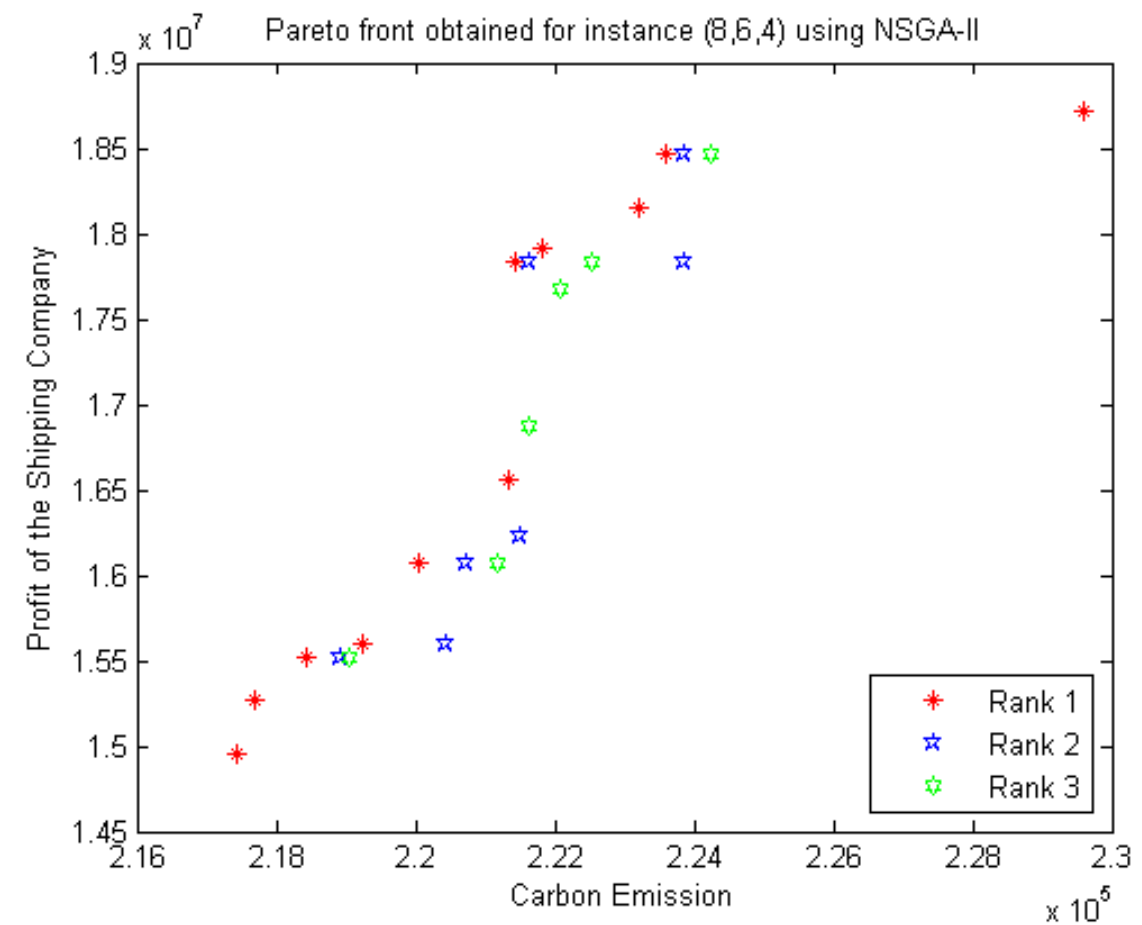

Figure 15: Pareto front generated using NSGA-II for problem instance (8-6-4) 


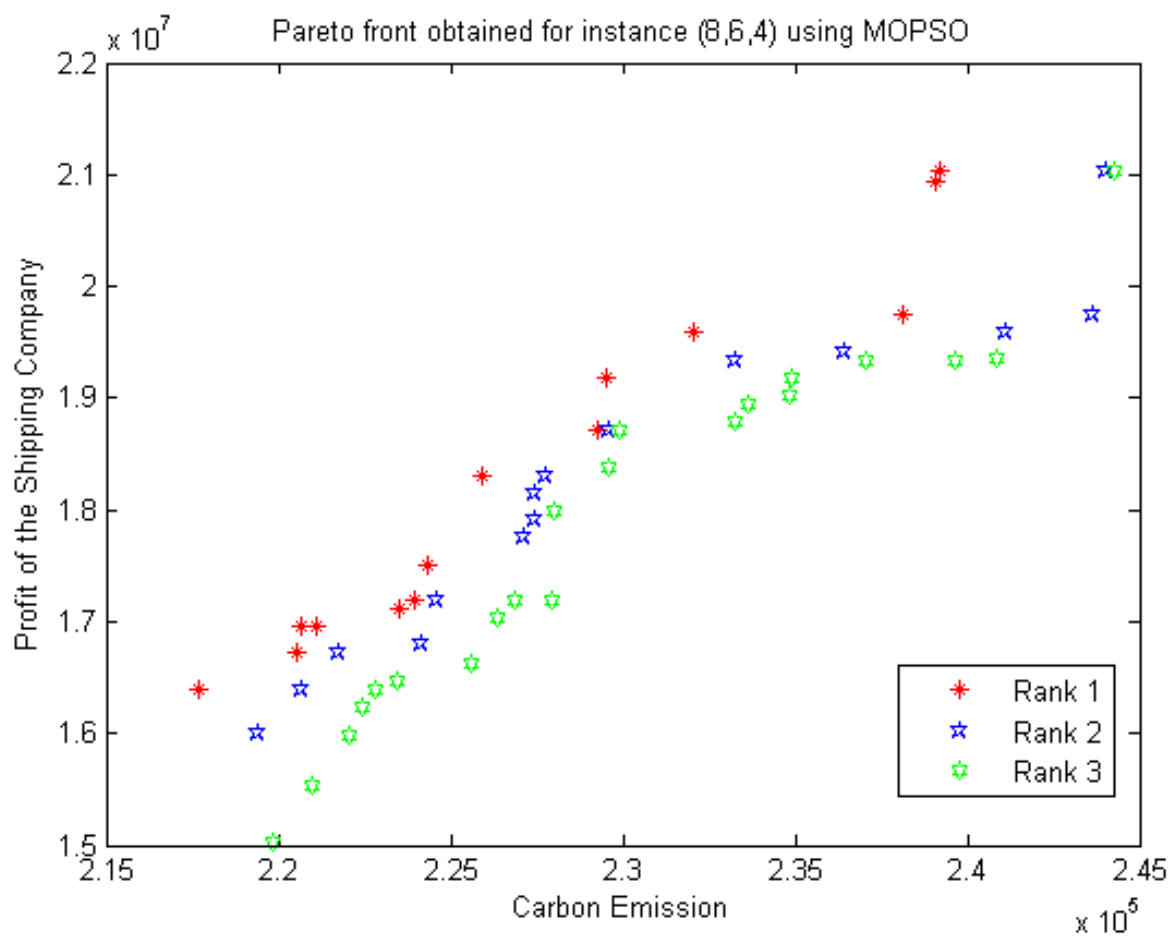

Figure 16: Pareto front generated using MOPSO for problem instance (8-6-4)

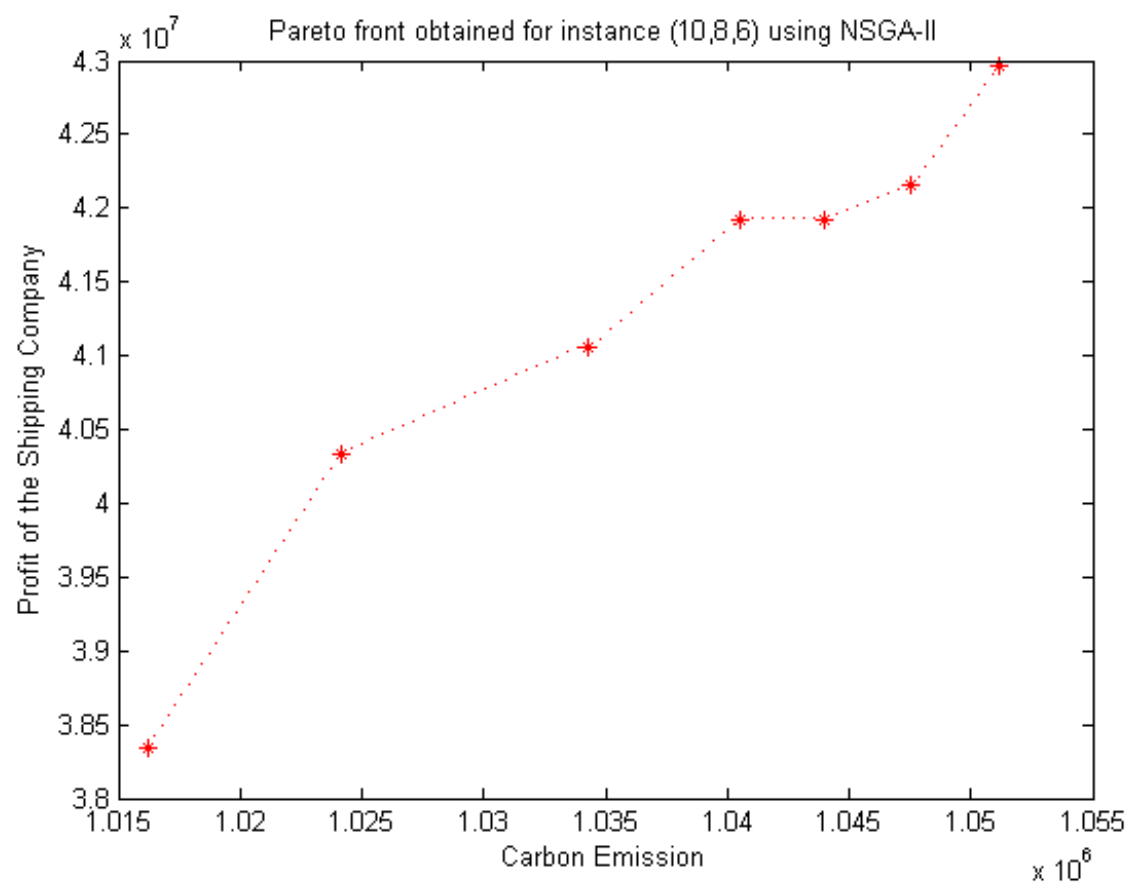

Figure 17: Pareto front generated using NSGA-II for problem instance (10-8-6) 


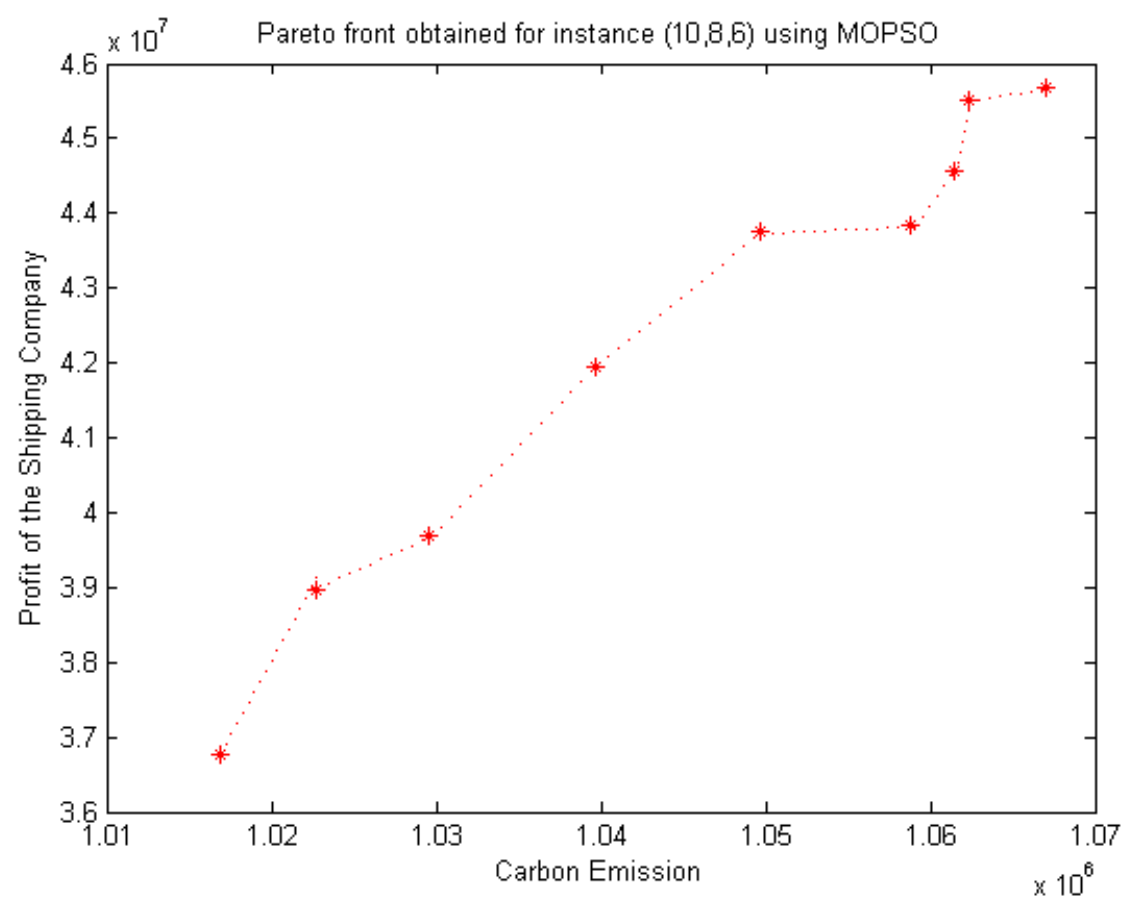

Figure 18: Pareto front generated using MOPSO for problem instance (10-8-6)

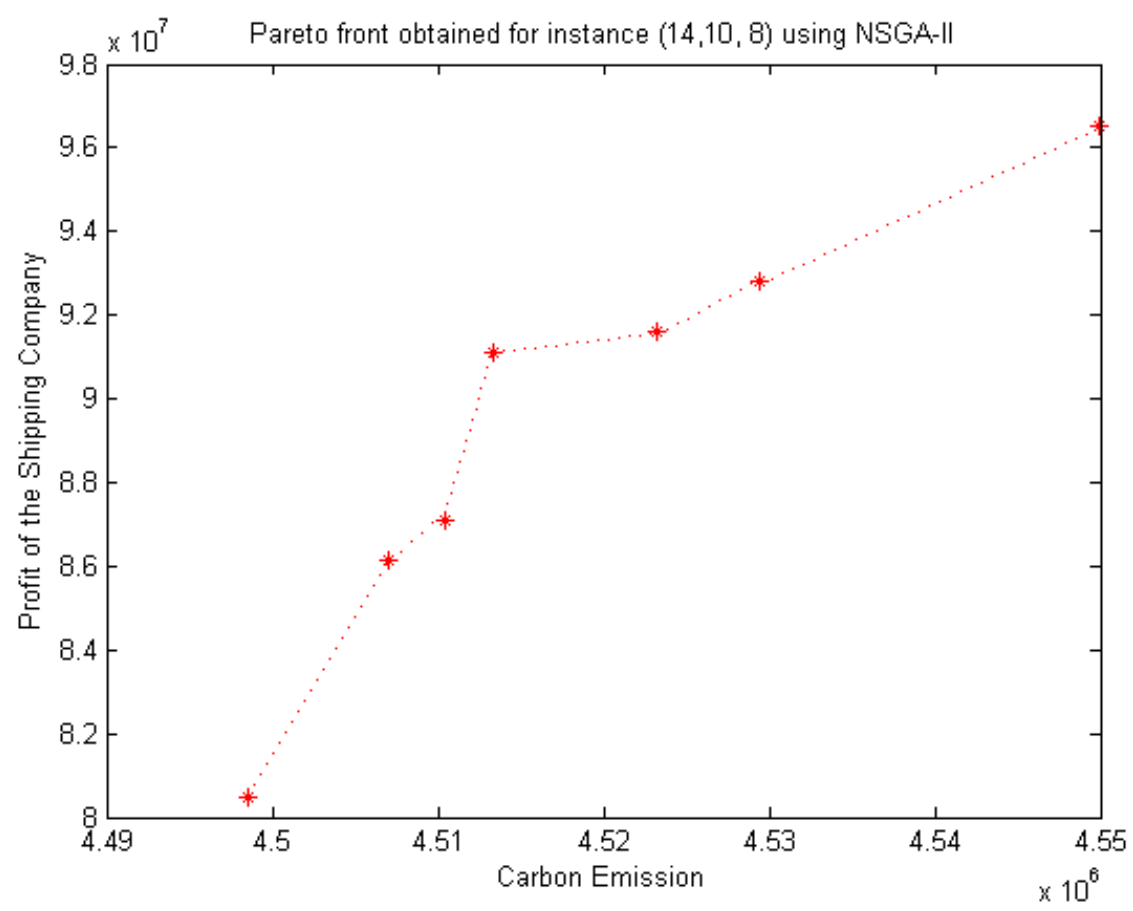

Figure 19: Pareto front generated using NSGA-II for problem instance (14-10-8) 


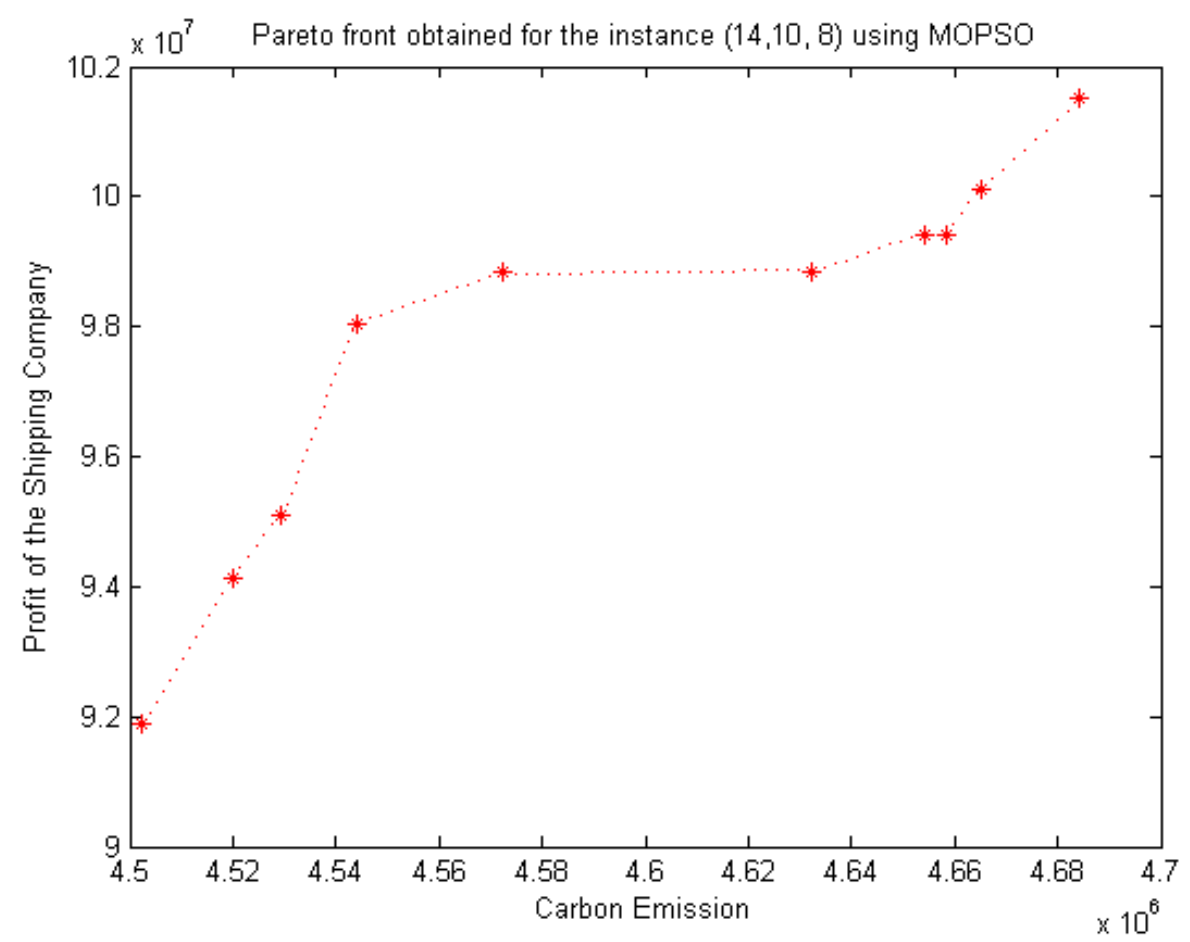

Figure 20: Pareto front generated using MOPSO for problem instance (14-10-8)

Table 2: Carbon emission incurred and revenue generated for each of the problem instances

\begin{tabular}{|c|c|c|c|c|c|}
\hline $\begin{array}{c}\text { Serial } \\
\text { No. }\end{array}$ & $\begin{array}{c}\text { Problem instances } \\
\text { (ports, periods, } \\
\text { ships) }\end{array}$ & $\begin{array}{c}\text { Carbon Emission } \\
\text { incurred using NSGA } \\
-\mathrm{II} \\
\text { (Tonne of } \mathrm{CO}_{2} \text { ) }\end{array}$ & $\begin{array}{c}\text { Carbon Emission } \\
\text { incurred using } \\
\text { MOPSO } \\
\text { (Tonne of } \mathrm{CO}_{2} \text { ) }\end{array}$ & $\begin{array}{c}\text { Profit obtained by } \\
\text { NSGA-II (USD) }\end{array}$ & $\begin{array}{c}\text { Profit obtained by } \\
\text { MOPSO (USD) }\end{array}$ \\
\hline 1 & $(3,3,2)$ & $1.503 \times 10^{3}$ & $1.458 \times 10^{3}$ & $2.377 \times 10^{6}$ & $2.377 \times 10^{6}$ \\
\hline 2 & $(5,3,3)$ & $1.023 \times 10^{4}$ & $9.838 \times 10^{3}$ & $5.225 \times 10^{6}$ & $5.389 \times 10^{6}$ \\
\hline 3 & $(8,6,4)$ & $2.192 \times 10^{5}$ & $2.205 \times 10^{5}$ & $15.598 \times 10^{6}$ & $16.716 \times 10^{6}$ \\
\hline 4 & $(10,8,6)$ & $1.034 \times 10^{6}$ & $1.058 \times 10^{6}$ & $41.054 \times 10^{6}$ & $43.850 \times 10^{6}$ \\
\hline 5 & $(14,10,8)$ & $4.529 \times 10^{6}$ & $4.523 \times 10^{6}$ & $95.092 \times 10^{6}$ & $91.592 \times 10^{6}$ \\
\hline
\end{tabular}

Table 3: Pareto solutions for the instances $(10,8,6)$ obtained using NSGA-II and MOPSO

\begin{tabular}{|c|c|c|c|c|}
\hline \multirow{2}{*}{$\begin{array}{l}\text { Number of } \\
\text { Pareto } \\
\text { solutions }\end{array}$} & \multicolumn{2}{|c|}{ Problem instance $(10,8,6)$, NSGA-II results } & \multicolumn{2}{|c|}{ Problem instance $(10,8,6)$, MOPSO results } \\
\hline & $\begin{array}{l}\text { Carbon Emission } \\
\text { (Tonne of } \mathrm{CO}_{2} \text { ) }\end{array}$ & $\begin{array}{l}\text { Profit } \\
\text { (USD) }\end{array}$ & $\begin{array}{c}\text { Carbon Emission } \\
\left(\text { Tonne of } \mathrm{CO}_{2} \text { ) }\right.\end{array}$ & $\begin{array}{l}\text { Profit } \\
\text { (USD) }\end{array}$ \\
\hline 1 & $1.040 \times 10^{6}$ & $41.922 \times 10^{6}$ & $1.049 \times 10^{6}$ & $43.759 \times 10^{6}$ \\
\hline 2 & $1.044 \times 10^{6}$ & $41.924 \times 10^{6}$ & $1.039 \times 10^{6}$ & $41.933 \times 10^{6}$ \\
\hline 3 & $1.051 \times 10^{6}$ & $42.964 \times 10^{6}$ & $1.016 \times 10^{6}$ & $36.752 \times 10^{6}$ \\
\hline 4 & $1.047 \times 10^{6}$ & $42.164 \times 10^{6}$ & $1.029 \times 10^{6}$ & $39.696 \times 10^{6}$ \\
\hline 5 & $1.034 \times 10^{6}$ & $41.054 \times 10^{6}$ & $1.062 \times 10^{6}$ & $45.514 \times 10^{6}$ \\
\hline 6 & $1.024 \times 10^{6}$ & $40.327 \times 10^{6}$ & $1.066 \times 10^{6}$ & $45.677 \times 10^{6}$ \\
\hline 7 & $1.016 \times 10^{6}$ & $38.344 \times 10^{6}$ & $1.058 \times 10^{6}$ & $43.850 \times 10^{6}$ \\
\hline 8 & & & $1.061 \times 10^{6}$ & $44.556 \times 10^{6}$ \\
\hline
\end{tabular}


Table 4: Pareto solutions for the instances $(14,10,8)$ obtained using NSGA-II and MOPSO

\begin{tabular}{|c|c|c|c|c|}
\hline \multirow{2}{*}{$\begin{array}{c}\text { Number of } \\
\text { Pareto } \\
\text { solutions }\end{array}$} & \multicolumn{2}{|c|}{ Problem instance $(14,10,8)$, NSGA-II results } & \multicolumn{2}{|c|}{ Problem instance $(14,10,8)$, MOPSO results } \\
\hline & $\begin{array}{l}\text { Carbon emission } \\
\text { (Tonne of } \mathrm{CO}_{2} \text { ) }\end{array}$ & $\begin{array}{l}\text { Profit } \\
\text { (USD) }\end{array}$ & $\begin{array}{l}\text { Carbon emission } \\
\text { (Tonne of } \mathrm{CO}_{2} \text { ) }\end{array}$ & $\begin{array}{l}\text { Profit } \\
\text { (USD) }\end{array}$ \\
\hline 1 & $4.529 \times 10^{6}$ & $95.092 \times 10^{6}$ & $4.498 \times 10^{6}$ & $80.483 \times 10^{6}$ \\
\hline 2 & $4.572 \times 10^{6}$ & $98.827 \times 10^{6}$ & $4.513 \times 10^{6}$ & $91.115 \times 10^{6}$ \\
\hline 3 & $4.543 \times 10^{6}$ & $98.054 \times 10^{6}$ & $4.529 \times 10^{6}$ & $92.791 \times 10^{6}$ \\
\hline 4 & $4.519 \times 10^{6}$ & $94.130 \times 10^{6}$ & $4.523 \times 10^{6}$ & $91.592 \times 10^{6}$ \\
\hline 5 & $4.502 \times 10^{6}$ & $91.895 \times 10^{6}$ & $4.507 \times 10^{6}$ & $86.164 \times 10^{6}$ \\
\hline 6 & $4.632 \times 10^{6}$ & $98.855 \times 10^{6}$ & $4.549 \times 10^{6}$ & $96.524 \times 10^{6}$ \\
\hline 7 & $4.654 \times 10^{6}$ & $99.408 \times 10^{6}$ & $4.510 \times 10^{6}$ & $87.118 \times 10^{6}$ \\
\hline 8 & $4.658 \times 10^{6}$ & $99.412 \times 10^{6}$ & & \\
\hline 9 & $4.665 \times 10^{6}$ & $100.124 \times 10^{6}$ & & \\
\hline 10 & $4.684 \times 10^{6}$ & $101.508 \times 10^{6}$ & & \\
\hline
\end{tabular}

Table 5. Sensitivity analysis conducted with respect to the tonnage of containerized cargo per centimetre of draft

\begin{tabular}{|c|c|c|c|c|c|c|c|}
\hline \multirow{2}{*}{$\begin{array}{l}\text { Problem } \\
\text { Instance } \\
\text { (ports, } \\
\text { periods, } \\
\text { ships) }\end{array}$} & \multirow{2}{*}{$\begin{array}{l}\text { Tonnage of } \\
\text { containerized } \\
\text { cargo per } \\
\text { centimetre of } \\
\text { draft }\end{array}$} & \multicolumn{2}{|c|}{ NSGA-II results } & \multirow[b]{2}{*}{$\begin{array}{l}\text { Percentage } \\
\text { increase or } \\
\text { decrease in } \\
\text { profit }\end{array}$} & \multicolumn{2}{|c|}{ MOPSO results } & \multirow[b]{2}{*}{$\begin{array}{c}\text { Percentage } \\
\text { difference } \\
\text { in profit }\end{array}$} \\
\hline & & $\begin{array}{l}\text { Carbon emission } \\
\text { (Tonne of } \mathrm{CO}_{2} \text { ) }\end{array}$ & $\begin{array}{l}\text { Profit } \\
\text { (USD) }\end{array}$ & & $\begin{array}{l}\text { Carbon emission } \\
\text { (Tonne of } \mathrm{CO}_{2} \text { ) }\end{array}$ & $\begin{array}{l}\text { Profit } \\
\text { (USD) }\end{array}$ & \\
\hline \multirow{4}{*}{$(14,10,8)$} & $50 \%$ increase & $4.506 \times 10^{6}$ & $145.036 \times 10^{6}$ & $\begin{array}{c}52.52 \% \\
\text { (increase) }\end{array}$ & $4.557 \times 10^{6}$ & $145.493 \times 10^{6}$ & $\begin{array}{c}58.84 \% \\
\text { (increase) }\end{array}$ \\
\hline & $25 \%$ increase & $4.512 \times 10^{6}$ & $120.224 \times 10^{6}$ & $\begin{array}{c}26.42 \% \\
\text { (increase) }\end{array}$ & $4.543 \times 10^{6}$ & $120.052 \times 10^{6}$ & $\begin{array}{c}31.07 \% \\
\text { (increase) }\end{array}$ \\
\hline & $25 \%$ decrease & $4.490 \times 10^{6}$ & $70.095 \times 10^{6}$ & $\begin{array}{c}26.28 \% \\
\text { (decrease) }\end{array}$ & $4.511 \times 10^{6}$ & $71.386 \times 10^{6}$ & $\begin{array}{c}22.06 \% \\
\text { (decrease) }\end{array}$ \\
\hline & $50 \%$ decrease & $4.539 \times 10^{6}$ & $47.078 \times 10^{6}$ & $\begin{array}{c}50.49 \% \\
\text { (decrease) }\end{array}$ & $4.522 \times 10^{6}$ & $49.394 \times 10^{6}$ & $\begin{array}{c}46.07 \% \\
\text { (decrease) }\end{array}$ \\
\hline \multirow{4}{*}{$(10,8,6)$} & $50 \%$ increase & $1.024 \times 10^{6}$ & $64.966 \times 10^{6}$ & $\begin{array}{c}58.24 \% \\
\text { (increase) }\end{array}$ & $1.044 \times 10^{6}$ & $62.453 \times 10^{6}$ & $\begin{array}{c}42.42 \% \\
\text { (increase) }\end{array}$ \\
\hline & $25 \%$ increase & $1.049 \times 10^{6}$ & $53.429 \times 10^{6}$ & $\begin{array}{c}30.14 \% \\
\text { (increase) }\end{array}$ & $1.052 \times 10^{6}$ & $53.544 \times 10^{6}$ & $\begin{array}{c}22.10 \% \\
\text { (increase) }\end{array}$ \\
\hline & $25 \%$ decrease & $1.041 \times 10^{6}$ & $31.838 \times 10^{6}$ & $\begin{array}{c}22.44 \% \\
\text { (decrease) }\end{array}$ & $1.057 \times 10^{6}$ & $32.975 \times 10^{6}$ & $\begin{array}{c}24.80 \% \\
\text { (decrease) }\end{array}$ \\
\hline & $50 \%$ decrease & $1.043 \times 10^{6}$ & $21.12 \times 10^{6}$ & $\begin{array}{c}48.55 \% \\
\text { (decrease) }\end{array}$ & $1.045 \times 10^{6}$ & $20.367 \times 10^{6}$ & $\begin{array}{c}53.55 \% \\
\text { (decrease) }\end{array}$ \\
\hline \multirow{4}{*}{$(8,6,4)$} & $50 \%$ increase & $2.155 \times 10^{5}$ & $24.356 \times 10^{6}$ & $\begin{array}{c}56.14 \% \\
\text { (increase) }\end{array}$ & $2.143 \times 10^{5}$ & $26.500 \times 10^{6}$ & $\begin{array}{c}58.53 \% \\
\text { (increase) }\end{array}$ \\
\hline & $25 \%$ increase & $2.189 \times 10^{5}$ & $19.155 \times 10^{6}$ & $\begin{array}{c}22.80 \% \\
\text { (increase) }\end{array}$ & $2.203 \times 10^{5}$ & $21.048 \times 10^{6}$ & $\begin{array}{c}25.91 \% \\
\text { (increase) }\end{array}$ \\
\hline & $25 \%$ decrease & $2.120 \times 10^{5}$ & $12.357 \times 10^{6}$ & $\begin{array}{c}20.77 \% \\
\text { (decrease) }\end{array}$ & $2.141 \times 10^{5}$ & $13.538 \times 10^{6}$ & $\begin{array}{c}19.01 \% \\
\text { (decrease) }\end{array}$ \\
\hline & $50 \%$ decrease & $2.190 \times 10^{5}$ & $8.839 \times 10^{6}$ & $\begin{array}{c}43.33 \% \\
\text { (decrease) }\end{array}$ & $2.185 \times 10^{5}$ & $8.859 \times 10^{6}$ & $\begin{array}{c}47.00 \% \\
\text { (decrease) }\end{array}$ \\
\hline
\end{tabular}




\subsection{Managerial Implication}

Shipping companies seek more revenue and, in the process, compromise on carbon emissions and fuel consumption. However, it is essential to maintain a suitable trade-off between carbon emissions incurred and profits earned. From the results, it is interpreted that carbon emissions related objectives should be mandatorily incorporated in the mathematical model to take into account the sustainability aspects of maritime transportation. There is growing awareness about incorporating sustainable practices within the domain of supply chain [54], and several companies are aiming to embrace sustainability aspects into their operations [55]. The mathematical model presented in the paper will help shipping company managers to mitigate carbon emissions from shipping logistics by implementing the slow steaming policy. The formulation presented in this paper captures the conflicting nature of the two objectives of a shipping company, earning profits while reducing carbon emissions. The result reveals the potential of the multi-objective optimization approach in examining the trade-off between carbon emissions incurred and profits earned by a shipping company.

\section{CONCLUSIONS}

This paper developed a multi-objective mathematical model addressing routing and scheduling of vessels in the maritime transportation domain, taking into consideration the time window concept, sustainability aspects and vessel draft restrictions. The mixed integer non-linear programming (MINLP) model presented takes into account profits earned by a shipping company and total carbon emissions incurred in a planning horizon as the two objectives. The slow steaming strategy has been employed in the model to compute the overall fuel consumed by a shipping company while at sea. Carbon emissions coefficients for Heavy Fuel Oil (HFO) and Marine Diesel Oil (MDO) help to estimate the total carbon emissions. The time window concept focuses on the improvement of the service level by penalizing the early arrival of vessels before the start of the time window and failing to finish their operations within the allotted time. A vessel's arrival and departure from a port depends on the high tide conditions. A vessel's draft restrictions are incorporated in the mathematical model to maintain a safety limit while operating at a port. Two efficient and intelligent search heuristics, namely Non-Dominated Sorting Genetic Algorithm - II (NSGA-II) and MultiObjective Particle Swarm Optimization (MOPSO), are employed to resolve the proposed formulation. The model is tested on medium and large sized problem instances and the results obtained portray the performance of the algorithms and validate the proposed mathematical model. Profits earned and carbon emissions incurred for all of the five problem instances are mentioned in the preceding sections. From the findings of the paper, it is clear that a suitable trade-off needs to be reached between profits earned and carbon emissions incurred as the competency of a shipping company depends on its sustainability. Insights derived from this research will help shipping companies to rethink their profit-making policies, bearing in mind relevant environmental reforms.

In future, the stochastic nature of the fuel price can be incorporated in the model to address the fuel cost incurred by shipping companies. Some of the assumptions in this model such as deterministic demand and single containerized cargo could be relaxed, and the problem could 
be extended to stochastic demand and multiple types of containerized cargo. More effective and efficient algorithms can be developed to obtained better results in less computational time.

Acknowledgement: The authors acknowledge the support provided by European Union EuropeAid-funded Project "EU-India Research \& Innovation Partnership for Efficient and Sustainable Freight Transportation (REINVEST)," Contract Number: R/141842. The contents of this publication are the sole responsibility of the authors of this paper and can in no way be taken to reflect the views of the European Union.

\section{REFERENCES}

[1] J. Sarkis, T. D. Bruijn, and Q. Zhu, "Guest editorial: Sustainability in engineering Management - setting the foundation for the path forward." IEEE Transactions on Engineering Management, vol. 60, no. 2, pp. 301-314, 2013.

[2] UNCTAD, "Review of Maritime Transport 2013," United Nations Publications, New York and Geneva. 2013.

[3] UNCTAD, "Review of Maritime Transport 2014," United Nations Publications, New York and Geneva. 2014.

[4] UNCTAD, "Review of Maritime Transport 2015," United Nations Publications, New York and Geneva. 2015.

[5] C. Kontovas and H. N. Psaraftis, "Reduction of emissions along the maritime intermodal container chain: operational models and policies," Maritime Policy \& Management, vol. 38, no. 4, pp. 451-469, 2011.

[6] Ø. Buhaug, J. J. Corbett, Ø. Endresen, V. Eyring, J. Faber, S. Hanayama, D. S. Lee, D. Lee, H. Lindstad, A. Z. Markowska, A. Mjelde, D. Nelissen, J. Nilsen, C. Pålsson, J. J. Winebrake, W. Wu, and K. Yoshida, "Second IMO GHG Study," London, UK: International Maritime Organisation (IMO), 2009.

[7] K. Cullinane and R. Bergqvist, "Emission control areas and their impact on maritime transport," Transportation Research Part D: Transport and Environment, vol. 28, no. May, pp. 1-5, 2014.

[8] E. Y. C. Wong, A. H. Tai, H. Y. K. Lau, and M. Raman, "An utility-based decision support sustainability model in slow steaming maritime operations," Transportation Research Part E: Logistics and Transportation Review, vol. 78, no. June, pp. 57-69, 2015.

[9] K. Fagerholt, N. T. Gausel, J. G. Rakke, and H. N. Psaraftis, "Maritime routing and speed optimization with emission control areas," Transportation Research Part C: Emerging Technologies, vol. 52, no. March, pp. 57-73, 2015. 
[10] Z. Yao, S. H. Ng, and L. H. Lee, "A study on bunker fuel management for the shipping liner services," Computers and Operations Research, vol. 39, no. 5, pp. 1160-1172, 2012.

[11] H. Andersson, K. Fagerholt, and K. Hobbesland, "Integrated maritime fleet deployment and speed optimization: Case study from RoRo shipping," Computers and Operations Research, vol. 55, no. March, pp. 233-240, 2015.

[12] J. Yin, L. Fan, Z. Yang, and K. X. Li, "Slow steaming of liner trade: its economic and environmental impacts," Maritime Policy \& Management, vol. 41, no. 2, pp. 149-158, Feb. 2014.

[13] I. Norstad, K. Fagerholt, and G. Laporte, "Tramp ship routing and scheduling with speed optimization," Transportation Research Part C: Emerging Technologies, vol. 19, no. 5, pp. 853-865, 2011.

[14] H. N. Psaraftis, and C. A. Kontovas, "Balancing the economic and environmental performance of maritime transportation." Transportation Research Part D: Transport and Environment, vol. 15, no. 8, pp. 458-462, 2010.

[15] H. N. Psaraftis, and C. A. Kontovas, "Speed models for energy-efficient maritime transportation: A taxonomy and survey." Transportation Research Part C: Emerging Technologies, vol. 26, no. pp. January, 331-351, 2013.

[16] N. Aydin, H. Lee and S. A. Mansouri, "Speed optimization and bunkering in liner shipping in the presence of uncertain service times and time windows at ports," European Journal of Operational Research, vol. 259, no. 1, pp. 143-154, 2017.

[17] S. A. Mansouri, H. Lee and O. Aluko, "Multi-objective decision support to enhance environmental sustainability in maritime shipping: a review and future directions." Transportation Research Part E: Logistics and Transportation Review, vol. 78, no. June, pp.3-18, 2015.

[18] D.P. Song, D. Li, and P. Drake, "Multi-objective optimization for planning liner shipping service with uncertain port times." Transportation Research Part E: Logistics and Transportation Review, vol. 84, no. December, pp. 1-22, 2015.

[19] X. Qi, and D.P. Song, "Minimizing fuel emissions by optimizing vessel schedules in liner shipping with uncertain port times." Transportation Research Part E: Logistics and Transportation Review, vol. 48, no. 4, pp. 863-880, 2012.

[20] H. Lindstad, B. E. Asbjørnslett, and A. H. Strømman, "Reductions in greenhouse gas emissions and cost by shipping at lower speeds." Energy Policy, vol. 39, no. 6, pp. 34563464, 2011.

[21] H. N. Psaraftis, and C. A. Kontovas, "Ship speed optimization: Concepts, models and combined speed-routing scenarios." Transportation Research Part C: Emerging Technologies, vol. 44, no. July, pp. 52-69, 2014. 
[22] F. Al-Khayyal and S.-J. Hwang, "Inventory constrained maritime routing and scheduling for multi-commodity liquid bulk, Part I: Applications and model," European Journal of Operational Research, vol. 176, no. 1, pp. 106-130, 2007.

[23] R. Grønhaug, M. Christiansen, G. Desaulniers, and J. Desrosiers, "A Branch-andPrice Method for a Liquefied Natural Gas Inventory Routing Problem," Transportation Science, vol. 44, no. 3, pp. 400-415, Aug. 2010.

[24] D. Ronen, "Marine inventory routing: shipments planning," Journal of the Operational Research Society, vol. 53, no. 1, pp. 108-114, Jan. 2002.

[25] N. Siswanto, D. Essam, and R. Sarker, "Solving the ship inventory routing and scheduling problem with undedicated compartments," Computers \& Industrial Engineering, vol. 61, no. 2, pp. 289-299, Sep. 2011.

[26] V. Goel, K. C. Furman, J.-H. Song, and A. S. El-Bakry, "Large neighborhood search for LNG inventory routing,” Journal of Heuristics, vol. 18, no. 6, pp. 821-848, Nov. 2012.

[27] H. Andersson, M. Christiansen, and G. Desaulniers, "A new decomposition algorithm for a liquefied natural gas inventory routing problem," International Journal of Production Research, vol. 54, no. 2, pp. 564-578, 2016.

[28] M. Stålhane, H. Andersson, M. Christiansen, J. F. Cordeau, and G. Desaulniers, "A branch-price-and-cut method for a ship routing and scheduling problem with split loads," Computers and Operations Research, vol. 39, no. 12, pp. 3361-3375, 2012.

[29] A. Agra, M. Christiansen, and A. Delgado, "Mixed Integer Formulations for a Short Sea Fuel Oil Distribution Problem," Transportation Science, vol. 47, no. 1, pp. 57-59, 2013.

[30] A. Agra, M. Christiansen, A. Delgado, and L. Simonetti, "Hybrid heuristics for a short sea inventory routing problem," European Journal of Operational Research, vol. 236, no. 3, pp. 924-935, 2014.

[31] J.-H. Song and K. C. Furman, "A maritime inventory routing problem: Practical approach," Computers \& Operations Research, vol. 40, no. 3, pp. 657-665, Mar. 2013.

[32] A. De, V. K. R. Mamanduru, A. Gunasekaran, N. Subramanian, and M. K. Tiwari, "Composite particle algorithm for sustainable integrated dynamic ship routing and scheduling optimization," Computers and Industrial Engineering, vol. 96, no. June, pp. 201-215, 2016.

[33] K. Fagerholt, "Ship scheduling with soft time windows: An optimization based approach," European Journal of Operational Research, vol. 131, no. 3, pp. 559-571, 2001.

[34] J. De Armas, E. Lalla-ruiz, C. Expósito-izquierdo, D. Landa-silva, and B. Meliánbatista, "A hybrid GRASP-VNS for ship routing and scheduling problem with discretized time windows," Engineering Applications of Artificial Intelligence, vol. 45, no. October, pp. 350-360, 2015. 
[35] J. Glomvik Rakke, M. Christiansen, K. Fagerholt, and G. Laporte, "The Traveling salesman problem with draft limits," Computers and Operations Research, vol. 39, no. 9, pp. 2161-2167, 2012.

[36] K. C. Furman, J.-H. Song, G. R. Kocis, M. K. McDonald, and P. H. Warrick, "Feedstock Routing in the ExxonMobil Downstream Sector," Interfaces, vol. 41, no. 2, pp. 149-163, Apr. 2011.

[37] M. Battarra, A. Alves, A. Subramanian, and E. Uchoa, "Exact algorithms for the traveling salesman problem with draft limits," European Journal of Operational Research, vol. 235, no. 1, pp. 115-128, 2014.

[38] S. A. Mirhassani and N. Abolghasemi, "A particle swarm optimization algorithm for open vehicle routing problem," Expert Systems with Applications, vol. 38, no. 9, pp. 11547$11551,2011$.

[39] P. P. Repoussis, C. D. Tarantilis, O. Bräysy, and G. Ioannou, "A hybrid evolution strategy for the open vehicle routing problem," Computers and Operations Research, vol. 37 , no. 3, pp. 443-455, 2010.

[40] K. Deb, S. Pratab, S. Agarwal, and T. Meyarivan, "A Fast and Elitist Multiobjective Genetic Algorithm: NGSA-II," IEEE Transactions on Evolutionary Computing, vol. 6, no. 2, pp. 182-197, 2002.

[41] S. Li, N. Wang, T. Jia, Z. He, and H. Liang, "Multiobjective Optimization for Multiperiod Reverse Logistics Network Design." IEEE Transactions on Engineering Management, vol. 63, no. 2, pp. 223-236, 2016.

[42] S. Kannan, S. Baskar, J. D. McCalley, and P. Murugan, "Application of NSGA-II algorithm to generation expansion planning." IEEE Transactions on Power systems, vol. 24, no. 1, pp. 454-461, 2009.

[43] P. Murugan, S. Kannan, and S. Baskar, "Application of NSGA-II algorithm to singleobjective transmission constrained generation expansion planning." IEEE Transactions on Power Systems, vol. 24, no. 4, pp. 1790-1797, 2009.

[42] S. Kannan, S. Baskar, J. D. McCalley, and P. Murugan, "Application of NSGA-II algorithm to generation expansion planning." IEEE Transactions on Power systems, vol. 24, no. 1, pp. 454-461, 2009.

[43] P. Murugan, S. Kannan, and S. Baskar, "Application of NSGA-II algorithm to singleobjective transmission constrained generation expansion planning." IEEE Transactions on Power Systems, vol. 24, no. 4, pp. 1790-1797, 2009.

[44] X. Li, and M. Li, "Multiobjective local search algorithm-based decomposition for multiobjective permutation flow shop scheduling problem." IEEE Transactions on Engineering Management, vol. 62, no. 4, pp. 544-557, 2015. 
[45] X. Li, and S. Ma, "Multiobjective Discrete Artificial Bee Colony Algorithm for Multiobjective Permutation Flow Shop Scheduling Problem With Sequence Dependent Setup Times." IEEE Transactions on Engineering Management, DOI: 10.1109/TEM.2016.2645790

[46] S. M. Mousavi, J. Sadeghi, S. T. A. Niaki, and M. Tavana, "A bi-objective inventory optimization model under inflation and discount using tuned Pareto-based algorithms: NSGA-II, NRGA, and MOPSO," Applied Soft Computing Journal, vol. 43, no. June, pp. 5772, 2016.

[47] C. Li, Q. Xiao, Y. Tang, and L. Li, "A method integrating Taguchi, RSM and MOPSO to CNC machining parameters optimization for energy saving," Journal of Cleaner Production, vol. 135, no. November, pp. 263-275, 2016.

[48] M. Tavana, Z. Li, M. Mobin, M. Komaki, and E. Teymourian, "Multi-objective control chart design optimization using NSGA-III and MOPSO enhanced with DEA and TOPSIS,” Expert Systems with Applications, vol. 50, no. May, pp. 17-39, 2016.

[49] N. Shukla, M. K. Tiwari, and D. Ceglarek, "Genetic-algorithms-based algorithm portfolio for inventory routing problem with stochastic demand." International Journal of Production Research, vol. 51, no. 1, pp. 118-137, 2013.

[50] N. Shukla, A. K. Choudhary, P. K. S. Prakash, K. J. Fernandes, and M. K. Tiwari, "Algorithm portfolios for logistics optimization considering stochastic demands and mobility allowance." International Journal of Production Economics, vol. 141, no. 1, pp. 146-166, 2013.

[51] N. Shukla, Y. Dashora, M. K. Tiwari, F. T. S. Chan, and T. C. Wong, "Introducing algorithm portfolios to a class of vehicle routing and scheduling problem." Proceedings of The 2nd International Conference on Operations and Supply Chain Management, pp. 1-10, 2008 .

[52] C.-I. Hsu and Y.-P. Hsieh, "Shipping economic analysis for ultra large containership," Journal of the Eastern Asia Society for Transportation Studies, vol. 6, no. 3, pp. 936-951, 2005.

[53] M. Christiansen, K. Fagerholt, B. Nygreen, and D. Ronen, "Maritime Transportation," vol. 14, no. 6, 2007.

[54] H. Metta, and F. Badurdeen, "Integrating sustainable product and supply chain design: modeling issues and challenges." IEEE Transactions on Engineering Management, vol. 60, no. 2, pp. 438-446, 2013.

[55] J. Sun, N. Sabbaghi, and W. Ashton, "Green Supply Chain Formation Through ByProduct Synergies.” IEEE Transactions on Engineering Management, vol. 64, no. 1, pp. 7082, 2017. 
[56] A. De, S. K. Kumar, A. Gunasekaran, and M. K. Tiwari, "Sustainable maritime inventory routing problem with time window constraints." Engineering Applications of Artificial Intelligence, 61, pp.77-95, 2017.

[57] A. De, A. Awasthi, and M. K. Tiwari, "Robust formulation for optimizing sustainable ship routing and scheduling problem”. IFAC-PapersOnLine, 48, no. 3, pp. 368-373, 2015.

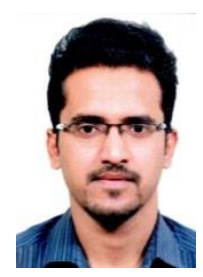

Arijit De received his B.Tech in Electronics and Communication Engineering and M.Tech degree in Industrial Engineering and Management from West Bengal University of Technology, Kolkata, India in the year 2010 and 2013 respectively. Currently, he is pursuing his Ph.D. degree in industrial and systems engineering at Indian Institute of Technology Kharagpur, India. His research interests include multi-objective optimization, meta-heuristics techniques and sustainable shipping operations. He was a visiting researcher at University of Hong Kong and published papers in Computers and Industrial Engineering (Elsevier) and Engineering Applications of Artificial intelligence (Elsevier).

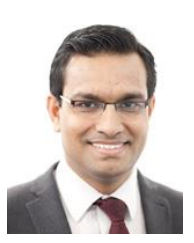

Dr Choudhary is a Reader (Prof.) in Supply Chain Management and the Co-Director of Undergraduate Studies, Management Science and Operations Management Group, School of Business and Economics, Loughborough University, Leicestershire, UK. Dr Choudhary focuses on interdisciplinary and industry-driven research to investigate Sustainability of Logistics and Supply Chain Industry. He has collaborated on various research projects funded by European Commission, European Union, British Council and other sources for $\mathrm{PhD}$. studentships. He has authored/co-authored over 90 research publications (including $40+$ in leading international journals). He is involved in several leadership roles (including Task Leader for External Strategic Partnerships and Research Challenge Leader for High-Value Manufacturing) and has developed a network of industrial and academic collaborators across the world. He was a Visiting Professor at Vienna University, IITs in India and a visiting researcher at Harvard Business School. He has served as a scientific committee member, session chair and keynote speaker of several international conferences, and delivered guest lectures to several universities. He is a guest editor for many international journals.

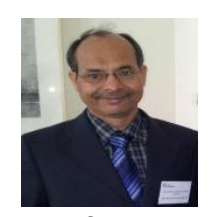

Prof. Manoj Kumar Tiwari is a Professor in the department of Industrial and Systems Engineering, Indian Institute of Technology Kharagpur, India. He has authored 250+ articles 
in peer-reviewed academic journals, including the European Journal of Operational Research, the Annals of Operations Research, and the International Journal of Production Research etc. His research interest includes Decision Support Models, Planning, Scheduling and Control Problems of Manufacturing System, Supply Chain Network, AI Applications in Manufacturing, Intelligent Search Technique, Nature Inspired Algorithm, Agent Technology and its Applications, Planning Problem of Assembly/ Disassembly, Continuous Improvement Techniques. He is holding the associate editorial position for Information Sciences (Elsevier), IEEE- System, Man and Cybernatics; Systems, International Journal of Production Research (Taylor and Francis), Computers and Industrial Engineering (Elsevier) etc. 